\title{
Rules-of-Thumb for Guiding Monetary Policy
}

\author{
William Poole
}

This article was originally published in the Board of Governors of the Federal Reserve System Open Market Policies and Operating Procedures_Staff Studies, July 1971. It is reprinted here as an addendum to these conference proceedings.

Federal Reserve Bank of St. Louis Review, July/August 2008, 90(4), pp. 447-97.

\section{INTRODUCTION}

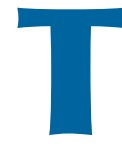

his study has been motivated by the recognition that the key to understanding policy problems is the analysis of uncertainty. Indeed, in the absence of uncertainty it might be said that there can be no policy problems, only administrative problems. It is surprising, therefore, that there has been so little systematic attention paid to uncertainty in the policy literature in spite of the fact that policymakers have repeatedly emphasized the importance of the unknown.

In the past, the formal models used in the analysis of monetary policy problems have almost invariably assumed complete knowledge of the economic relationships in the model. Uncertainty is introduced into the analysis, if at all, only through informal consideration of how much difference it makes if the true relationships differ from those assumed by the policymakers. In this study, on the other hand, uncertainty plays a key role in the formal model.

Since this study is so long, a few comments at the outset may assist the reader in finding his way through it. The remainder of this introduc- tory section outlines the structure of the study so that the reader can see how the various parts fit together. The reader interested only in a summary of the analysis and empirical findings should read this introductory section and then turn directly to the summary in Section V. This summary concentrates on the theoretical analysis while only briefly stating the most important empirical findings. It omits completely the technical details of both the theoretical and empirical work. The reader interested in the technical details should, of course, turn to the appropriate parts of Sections I through IV. Insofar as possible these sections have been written so that the reader can understand any one section without having to wade through all of the other sections.

Section I contains the theoretical argument comparing interest rates and the money stock as policy-control variables under conditions of uncertainty. The analysis is verbal and graphical, using the simple Hicksian IS-LM model with random terms added. This model is general enough to include both Keynesian and monetarist outlooks, depending on the specific assumptions as to the shapes of the functions. Since the theoretical analysis emphasizes the importance of the relative

William Poole is a former president of the Federal Reserve Bank of St. Louis. At the time this article was written, he was a senior economist in the special studies section of the division of research and statistics at the Board of Governors of the Federal Reserve System. Joan Walton, Lillian Humphrey, and Debra Bellows provided research assistance.

(C) 2008, The Federal Reserve Bank of St. Louis. The views expressed in this article are those of the author(s) and do not necessarily reflect the views of the Federal Reserve System, the Board of Governors, or the regional Federal Reserve Banks. Articles may be reprinted, reproduced, published, distributed, displayed, and transmitted in their entirety if copyright notice, author name(s), and full citation are included. Abstracts, synopses, and other derivative works may be made only with prior written permission of the Federal Reserve Bank of St. Louis. 
stability of the expenditures and money demand functions, an examination of the evidence on relative stability appears in Section II.

Given the conclusion of Section II on the superiority of a policy operating through adjustments in the money stock, the next question is how the money stock should be adjusted to achieve the best results. While policymakers generally look askance at suggestions for policy rules, the only way that economists can give long-run advice is in terms of rules. That is to say, the economist is not being helpful at all if he in effect says, "Look at the rate of inflation, at the rate of unemployment, at the forecasts of the government budget deficit, and at other relevant factors, and then act appropriately." Advice requires the specification of exactly how policy should be adjusted, and for this advice to be more than an ad hoc recommendation for the current situation, it must involve specification of how the money stock or some other control variable should be adjusted under hypothetical future conditions of inflation, unemployment, and so forth. The purpose of Section III is to develop such a rule-of-thumb, or policy guideline, based on the theoretical and empirical analyses of Sections I and 11.

A number of technical problems of monetary control are examined in Section IV. After a short introduction to the issues, the first part of this section discusses the relative merits of a number of monetary aggregates including various reserve measures, the narrowly and broadly defined money stocks, and bank credit. The second part examines whether policy should specify desired rates of change of an aggregate in terms of weekly, monthly, or quarterly averages, or in some other manner. The third part examines in a very incomplete fashion a few of the problems of adjusting open market operations so as to reach the desired level of an aggregate.

Finally, Section V consists of a summary of Sections I through IV. To avoid undue repetition, woven into this summary section are a number of general observations not examined in the other sections.

\section{THE THEORY OF MONETARY POLICY UNDER UNCERTAINTY}

\section{Basic Concepts}

The theory of optimal policy under uncertainty has provided many insights into actual policy problems (Theil, 1964; Brainard, 1967; Holt, 1962; Poole, 1970). While much of this theory is not accessible to the nonmathematical economist, it is possible to explain the basic ideas without resort to mathematics.

The obvious starting point is the observation that with our incomplete understanding of the economy and our inability to predict accurately the occurrence of disturbing factors such as strikes, wars, and foreign exchange crises, we cannot expect to hit policy goals exactly. Some periods of inflation or unemployment are unavoidable. The inevitable lack of precision in reaching policy goals is sometimes recognized by saying that the goals are "reasonably" stable prices and "reasonably" full employment.

While the observation above is trite, its implications are not. Two points are especially important. First, policy should aim at minimizing the average size of errors. Second, policy can be judged only by the average size of errors over a period of time and not by individual episodes. Because this second point is particularly subject to misunderstanding, it needs further amplification.

Since policymakers operate in a world that is inherently uncertain, they must be judged by criteria appropriate to such a world. Consider the analogy of betting on the draw of a ball from an urn with nine black balls and one red ball. Anyone offered a $\$ 2$ payoff for a $\$ 1$ bet would surely bet on a black ball being drawn. If the draw produced the red ball, no one would accuse the bettor of a stupid bet. Similarly, the policymaker must play the economic odds. The policymaker should not be accused of failure if an inflation occurs as the result of an improbable and unforeseeable event.

Now consider the reverse situation from that considered in the previous paragraph. Suppose the bettor with the same odds as above bets on the red ball and wins. Some would claim that the bet was brilliant, but assuming that the draw was not 
rigged in any way, the bet, even though a winning one, must be judged foolish. It is foolish because, on the average, such a betting strategy will lead to substantially worse results than the opposite strategy. Betting on red will prove brilliant only one time out of 10 , on the average. Similarly, a particular policy action may be a bad bet even though it works in a particular episode.

There is a well-known tendency for gamblers to try systems that according to the laws of probability cannot be successful over any length of time. Frequently, a gambler will adopt a foolish system as the result of an initial chance success such as betting on red in the above example. The same danger exists in economic policy. In fact, the danger is more acute because there appears to be a greater chance to "beat the system" by applying economic knowledge and intuition. There can be no doubt that it will become increasingly possible to improve on simple, naive policies through sophisticated analysis and forecasting and so in a sense "beat the system." But even with improved knowledge some uncertainty will always exist, and therefore so will the tendency to attempt to perform better than the state of knowledge really permits.

Whatever the state of knowledge, there must be a clear understanding of how to cope with uncertainty, even though the degree of uncertainty may have been drastically reduced through the use of modern methods of analysis. The principal purpose of this section is to improve understanding of the importance of uncertainty for policy by examining a simple model in which the policy problem is treated as one of minimizing errors on the average. Particular emphasis is placed on whether controlling policy by adjusting the interest rate or by adjusting the money stock will lead to smaller errors on the average. The basic argument is designed to show that the answer to which policy variable-the interest rate or the money stock-minimizes average errors depends on the relative stability of the expenditures and money demand functions and not on the values of parameters that determine whether monetary policy is in some sense more or less "powerful" than fiscal policy.

\section{Figure 1}

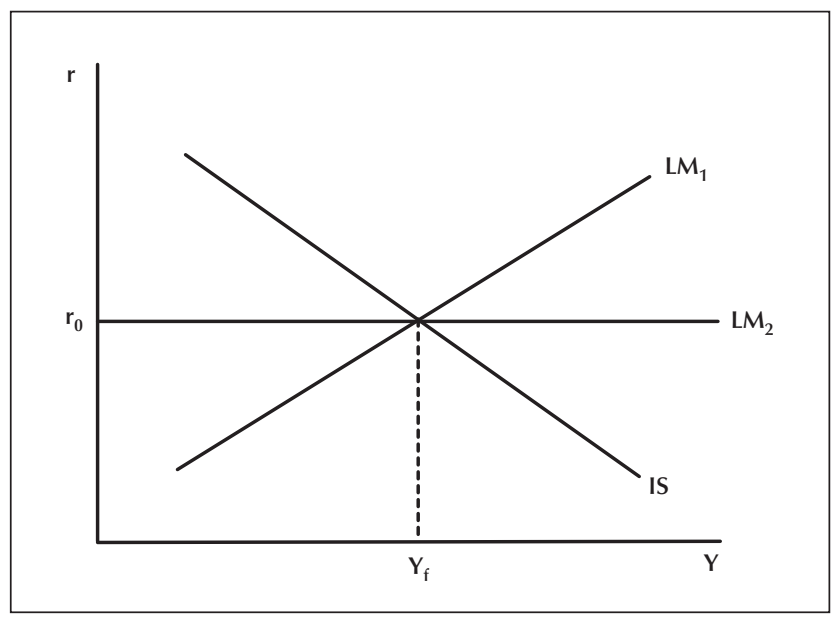

SOURCE: Originally published version, p. 139.

\section{Monetary Policy Under Uncertainty in a Keynesian Model'1}

The basic issues concerning the importance of uncertainty for monetary policy may be examined within the Hicksian $I S-L M$ version of the Keynesian system. This elementary model has two sectors, an expenditure sector and a monetary sector, and it assumes that the price level is fixed in the short run. ${ }^{2}$ Consumption, investment, and government expenditures functions are combined to produce the IS function in Figure 1, while the demand and supply of money functions are combined to produce the $L M$ function. If monetary policy fixes the stock of money, then the resulting $L M$ function is $L M_{1}$, while if policy fixes the interest rate at $r_{0}$ the resulting $L M$ function is $L M_{2}$. It is assumed that incomes above "full employment income" are undesirable due to inflationary pressures while incomes below full employment income are undesirable due to unemployment.

If the positions of all the functions could be predicted with no errors, then to reach full employment income, $Y_{f}$, it would make no differ-

1 For the most part this section represents a verbal and graphical version of the mathematical argument in Poole (1970).

2 Simple presentations of this model may be found in Reynolds (1969, pp. 275-82) and Samuelson (1967, pp. 327-32). 


\section{Figure 2}

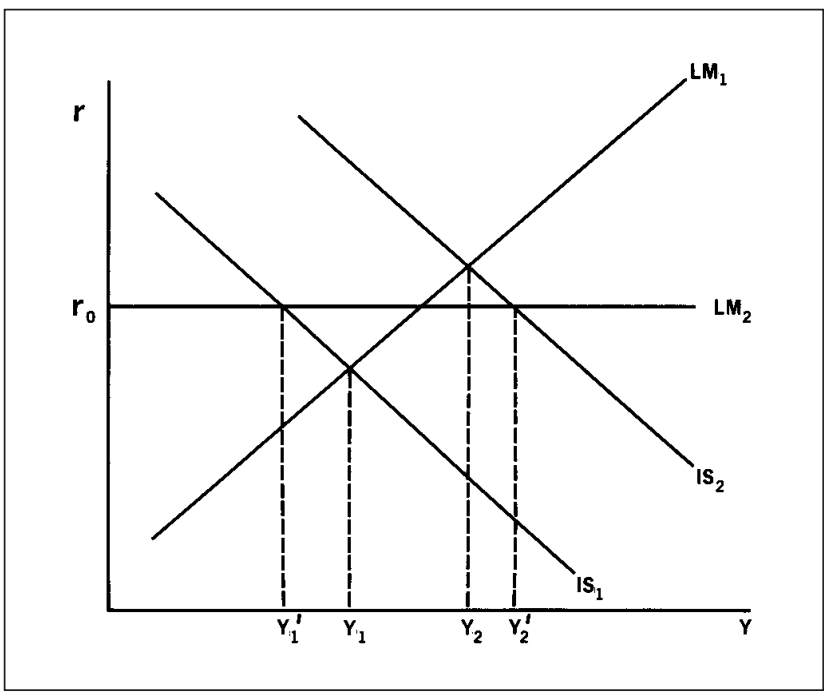

SOURCE: Originally published version, p. 141.

ence whether policy fixed the money stock or the interest rate. All that is necessary in either case is to set the money stock or the interest rate so that the resulting $L M$ function will cut the IS function at the full employment level of income.

Significance of Disturbances. The positions of the functions are, unfortunately, never precisely known. Consider first uncertainty over the position of the IS function-which, of course, results from instability in the underlying consumption and investment functions-while retaining the unrealistic assumption that the position of the $L M$ function is known. What is known about the IS function is that it will lie between the extremes of $I S_{1}$ and $I S_{2}$ in Figure 2. If the money stock is set at some fixed level, then it is known that the $L M$ function will be $L M_{1}$, and accordingly income will be somewhere between the extremes of $Y_{1}$ and $Y_{2}$. On the other hand, suppose policymakers follow an interest rate policy and set the interest rate at $r_{0}$. In this case income will be somewhere between $Y_{1}^{\prime}$ and $Y_{2}^{\prime}$, a wider range than $Y_{1}$ to $Y_{2}$, and so the money stock policy is superior to the interest rate policy. ${ }^{3}$

3 In Figure 2 and the following diagrams, the outcomes from a money stock policy will be represented by unprimed Y's, while

\section{Figure 3}

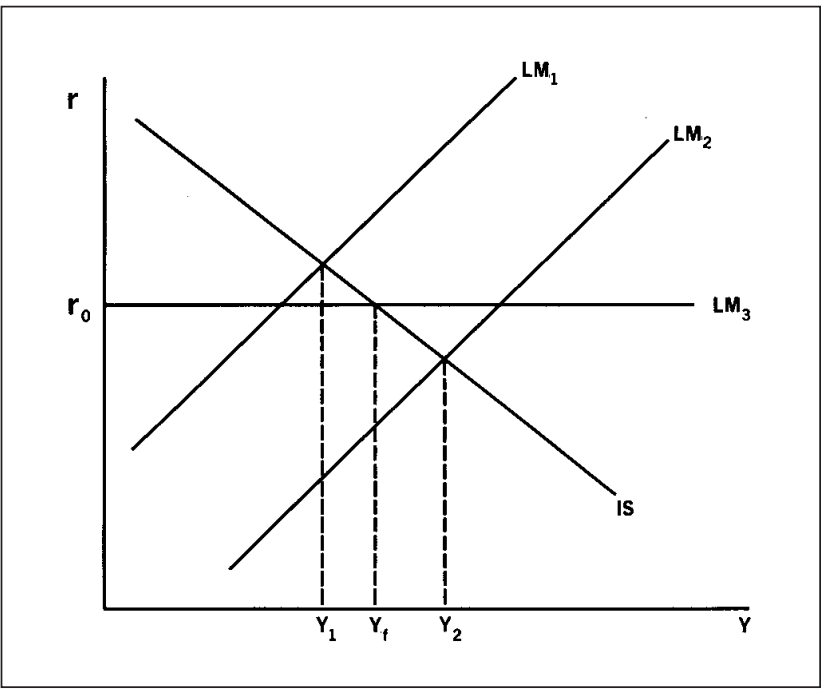

SOURCE: Originally published version, p. 140.

The money stock policy is superior because an unpredictable disturbance in the IS function will affect the interest rate, which in turn will produce spending changes that partly onset the initial disturbance.

The opposite polar case is illustrated in Figure 3. Here it is assumed that the position of the IS function is known with certainty, while unpredictable shifts in the demand for money cause unpredictable shifts in the $L M$ function if a money stock policy is followed. With a money stock policy, income may end up anywhere between $Y_{1}$ and $Y_{2}$. But an interest rate policy can fix the $L M$ function at $L M_{3}$ so that it cuts the IS function at the full employment level of income, $Y_{f}$. With an interest rate policy, unpredictable shifts in the demand for money are not permitted to affect the interest rate; instead, in the process of fixing the interest rate the policymakers adjust the stock of money in response to the unpredictable shifts in the demand for money.

In practice, of course, it is necessary to cope with uncertainty in both the expenditure and monetary sectors. This situation is depicted in

the outcomes from an interest rate policy will be represented by primed $Y$ 's. 


\section{Figure 4}

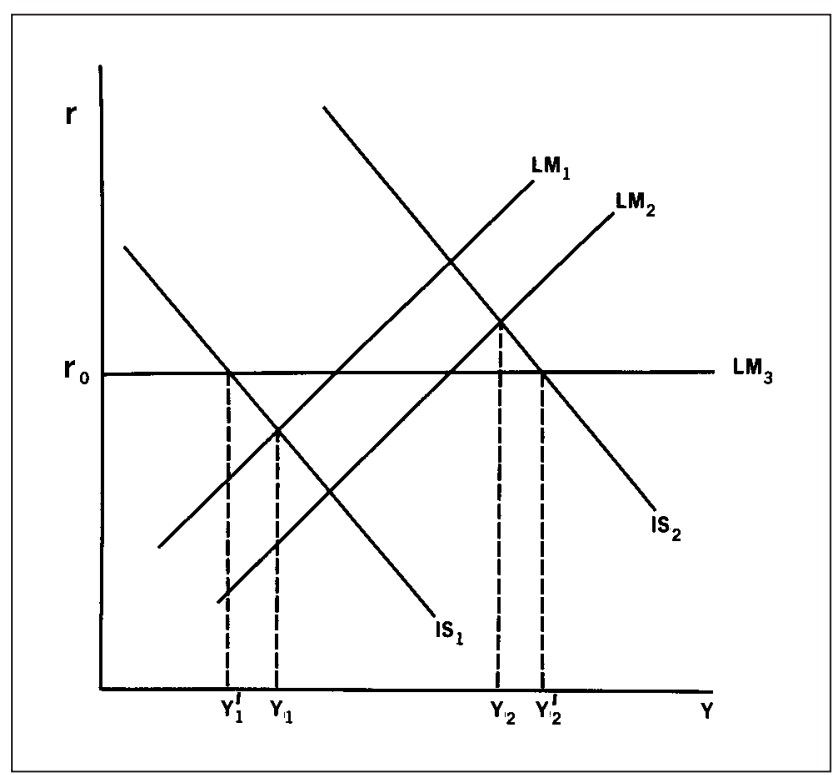

SOURCE: Originally published version, p. 141.

Figure 4, where the unpredictable disturbances are larger in the expenditure sector, and in Figure 5 where the unpredictable disturbances are larger in the monetary sector.

The situation is even more complicated than shown in Figures 4 and 5 by virtue of the fact that the disturbances in the two sectors may not be independent. To illustrate this case, consider Figure 5 in which the interest rate policy is superior to the money stock policy if the disturbances are independent. Suppose that the disturbances were connected in such a way that disturbances on the $L M_{1}$ side of the average $L M$ function were always accompanied by disturbances on the $I S_{2}$ side of the average $I S$ function. This would mean that income would never go as low as $Y_{1}$, but rather only as low as the intersection of $L M_{1}$ and $I S_{2}$, an income not as low as $Y_{1}^{\prime}$ under the interest rate policy. Similarly, the highest income would be given by the intersection of $L M_{2}$ and $I S_{1}$, an income not so high as $Y_{2}^{\prime}{ }^{4}$

4 The diagram could obviously have been drawn so that an interest rate policy would be superior to a money stock policy even though there was an inverse relationship between the shifts in the IS and $L M$ functions. However, inverse shifts always reduce the margin

\section{Figure 5}

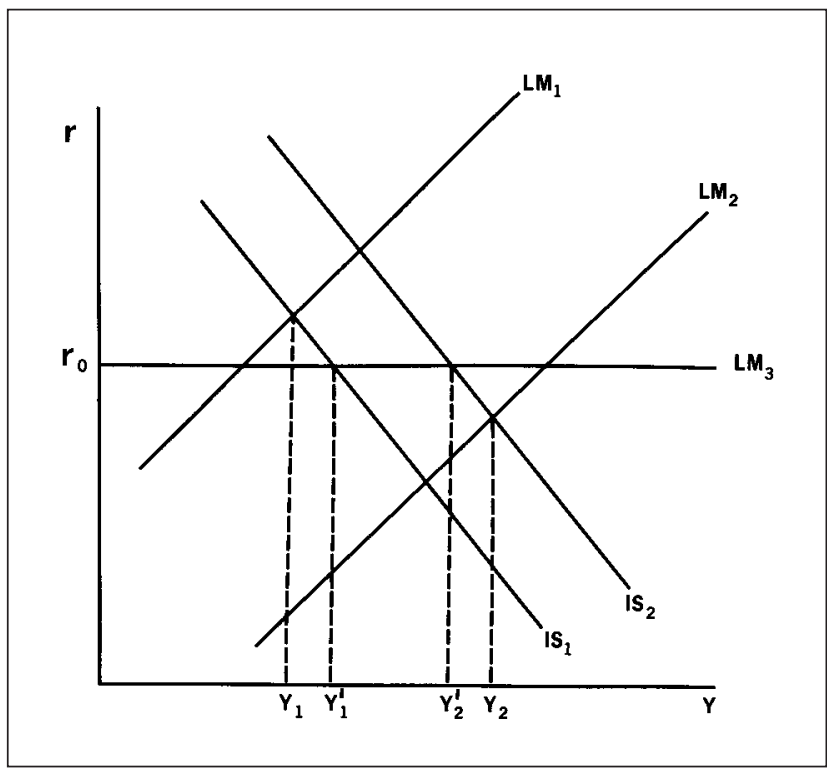

SOURCE: Originally published version, p. 141.

Importance of Interest Elasticities and Other Parameters. So far the argument has concentrated entirely on the importance of the relative sizes of expenditure and monetary disturbances. But is it also important to consider the slopes of the functions as determined by the interest elasticities of investment and of the demand for money, and by other parameters? Consider the pair of IS functions, $I S_{1}$ and $I S_{2}$, as opposed to the pair, $I S_{3}$ and $I S_{4}$, in Figure 6. Each pair represents the maximum and minimum positions of the IS function as a result of disturbances, but the pairs have different slopes. Each pair assumes the same maximum and minimum disturbances, as shown by the fact that the horizontal distance between $I S_{1}$ and $I S_{2}$ is the same as between $I S_{3}$ and $I S_{4}$. For convenience, but without loss of generality, the functions have been drawn so that under an interest rate policy represented by $L M_{2}$ both pairs of IS functions produce the same range of incomes. To keep the diagram from becoming

of superiority of an interest rate policy, possibly to the point of making a money stock policy superior. Conversely, positively related shifts favor an interest rate policy. 
Poole

Figure 6

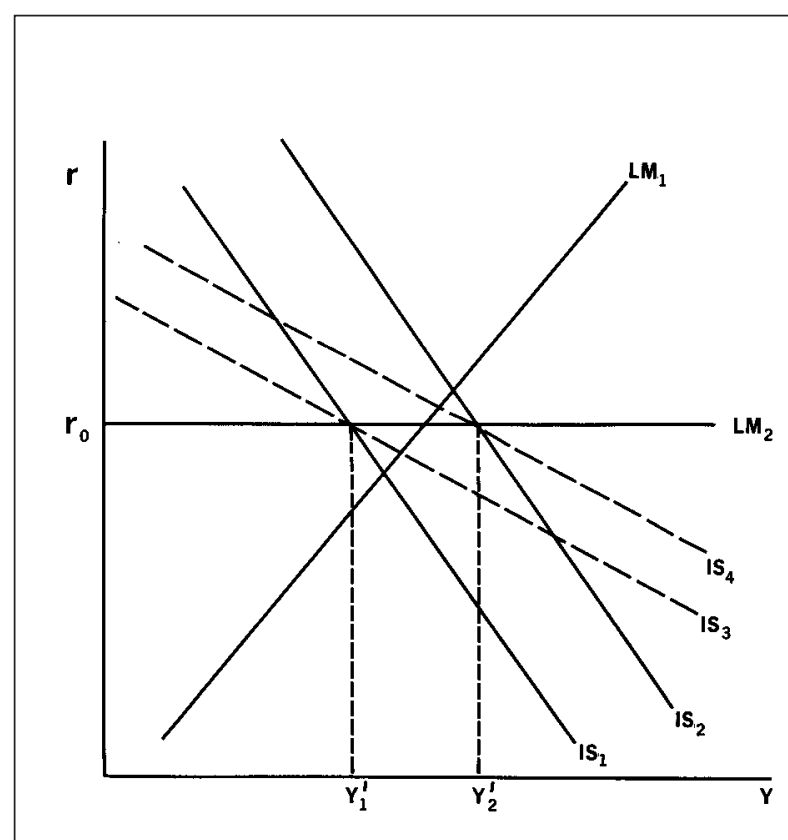

SOURCE: Originally published version, p. 141.

Figure 8

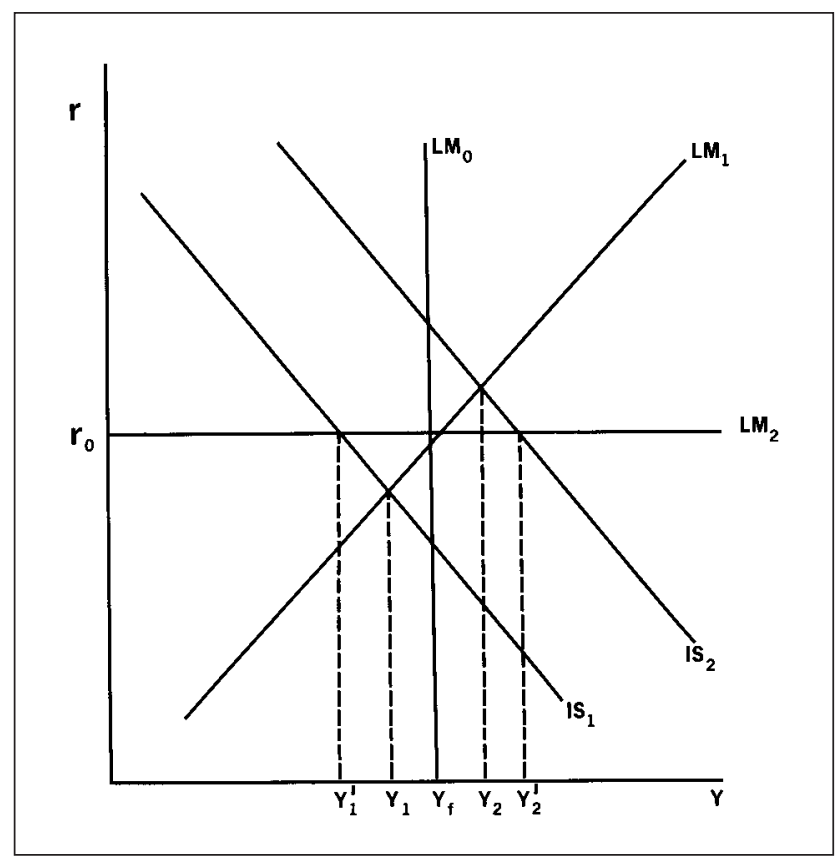

SOURCE: Originally published version, p. 143.
Figure 7

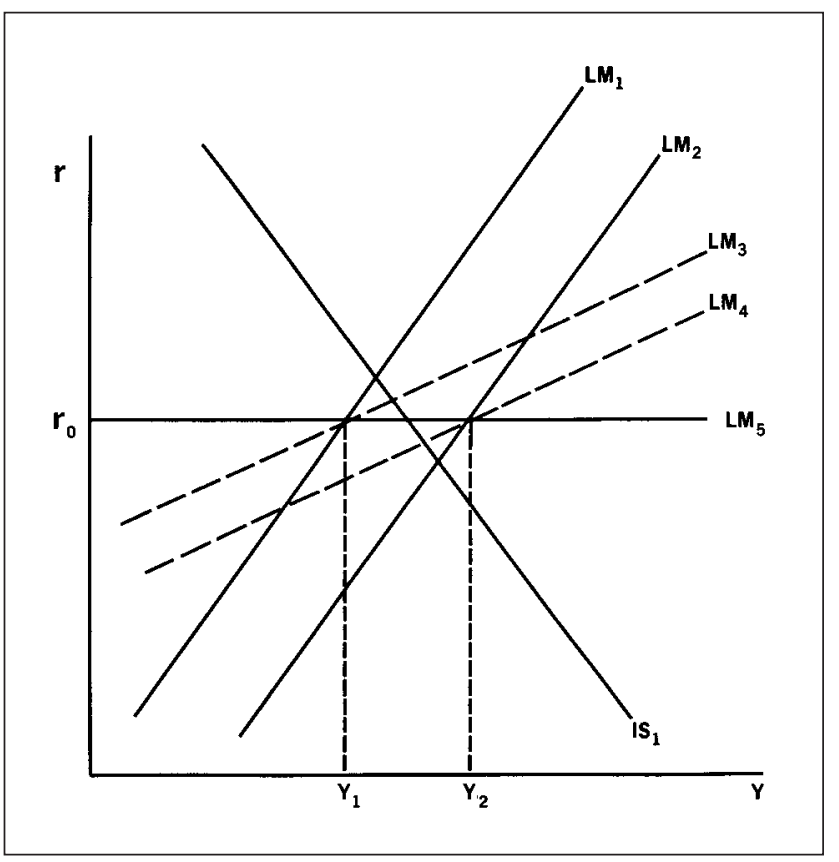

SOURCE: Originally published version, p. 141.

Figure 9

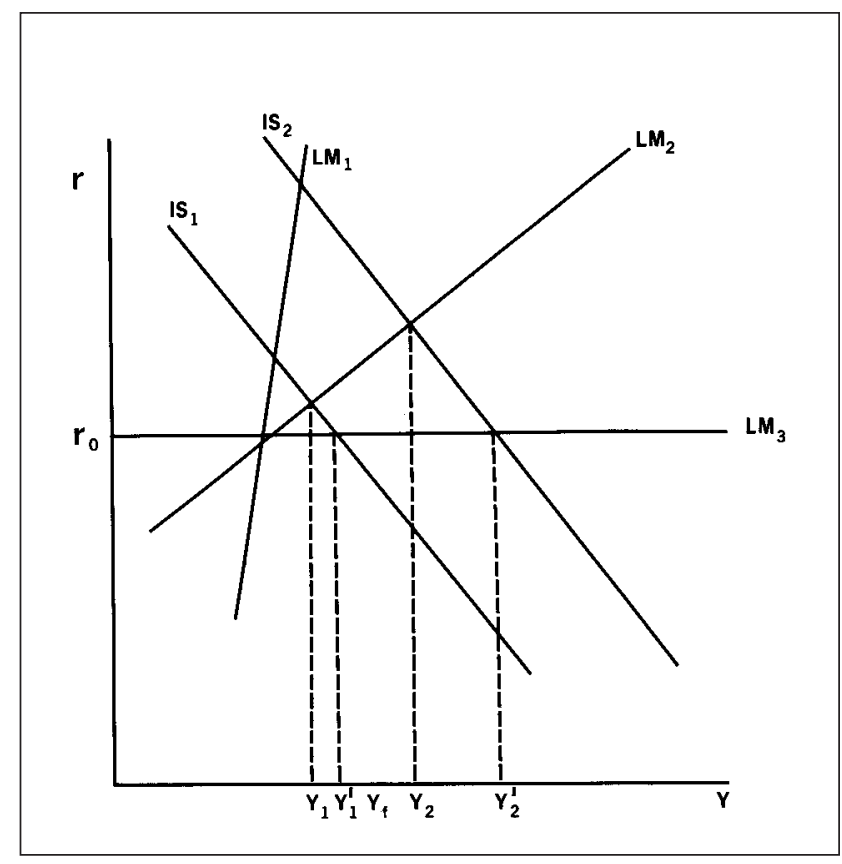

SOURCE: Originally published version, p. 143.

452 JULY/AUGUST 2008

FEDERAL RESERVE BANK OF ST. LOUIS REVIEW 
too messy, only one $L M$ function, $L M_{1}$, under a money stock policy has been drawn. Now consider disturbances that would shift $L M_{1}$ back and forth. From Figure 6 it is easy to see that if shifts in $L M_{1}$ would lead to income fluctuations greater than from $Y_{1}^{\prime}$ to $Y_{2}^{\prime}$-which fluctuations would occur under an interest rate policy - then an interest policy would be preferred regardless of whether we have the pair $I S_{1}$ and $I S_{2}$, or the pair $I S_{3}$ and $I S_{4}$.

The importance of the slope of the $L M$ function is investigated in Figure 7 for the two $L M$ pairs, $L M_{1}$ and $L M_{2}$, and $L M_{3}$ and $L M_{4}$. The functions have been drawn so that each pair represents different slopes but an identical range of disturbances. It is clear that if shifts in $I S_{1}$ are small enough, then an interest rate policy will be preferred regardless of which pair of $L M$ functions prevails. Conversely, if a money stock policy is preferred under one pair of $L M$ functions because of the shifts in the IS function, then a money stock policy will also be preferred under the other pair of $L M$ functions.

The upshot of this analysis is that the crucial issue for deciding upon whether an interest rate or a money stock policy should be followed is the relative size of the disturbances in the expenditure and monetary sectors. Contrary to much recent discussion, the issue is not whether the interest elasticity of the demand for money is relatively low or whether fiscal policy is more or less "powerful" than monetary policy.

To avoid possible confusion, it should be emphasized that the above conclusion is in terms of the choice between a money stock policy and an interest rate policy. However, if a money stock policy is superior, then the steeper the $L M$ function is, the lower the range of income fluctuation, as can be seen from Figure 7. It is also clear from Figure 6 that under an interest rate policy an error in setting the interest rate will lead to a larger error in hitting the income target if the IS function is relatively flat than if it is relatively steep. But these facts do not affect the choice between interest rate and money stock policies.

The "Combination" Monetary Policy. Up to this point the analysis has concentrated on the choice of either the interest rate or the money stock as the policy variable. But it is also possible to consider a "combination" policy that works through the money stock and the interest rate simultaneously. An understanding of the combination policy may be obtained by further consideration of the cases depicted in Figures 2 and 7.

In Figure 8 the disturbances, as in Figure 2, are entirely in the expenditure sector. As was seen in Figure 2, the result obtained by fixing the money stock so that $L M_{1}$ prevailed was superior to that obtained by fixing the interest rate so that $L M_{2}$ prevailed. But now suppose that instead of fixing the money stock, the money stock were reduced every time the interest rate went up and increased every time the interest rate went down. This procedure would, of course, increase the amplitude of interest rate fluctuations. ${ }^{5}$ But if the proper relationship between the money stock and the interest rate could be discovered, then the $L M$ function could be made to look like $L M_{0}$ in Figure 8. The result would be that income would be pegged at $Y_{f}$. Disturbances in the IS function would produce changes in the interest rate, which in turn would produce spending changes sufficient to completely offset the effect on income of the initial disturbance.

The most complicated case of all to explain graphically is that in which it is desirable to increase the money stock as the interest rate rises and decrease it as the interest rate falls. In Figure 9 the leftmost position of the $L M$ function as a result of disturbances is $L M_{1}$ when the money stock is fixed and is $L M_{2}$ when the combination policy of introducing a positive money-interest relationship is followed. The rightmost positions of the $L M$ functions under these conditions are not shown in the diagram. When the interest rate is pegged, the $L M$ function is $L M_{3}$. If either $L M_{1}$ or $L M_{2}$ prevails, the intersection with $I S_{1}$ produces the lowest income, which is below the $Y_{1}^{\prime}$ level

\footnotetext{
5 The increased fluctuations in interest rates must be carefully interpreted. In this model the IS function is assumed to fluctuate around a fixed-average position. However, in more complicated models involving changes in the average position of the IS function, perhaps through the operation of the investment accelerator, interest rate fluctuations may not be increased by the policy being discussed in the text. By increasing the stability of income over a period of time, the policy would increase the stability of the IS function in Figure 8 and thereby reduce interest rate fluctuations.
} 
obtained with $L M_{3}$. But in the case of $L M_{2}$, income at $Y_{1}$ is only a little lower than at $Y_{1}^{\prime}$, whereas when $I S_{2}$ prevails, $L M_{2}$ is better than $L M_{3}$ by the difference between $Y_{2}$ and $Y_{2}^{\prime}$. Since the gap between $Y_{2}$ and $Y_{2}^{\prime}$ is larger than that between $Y_{1}$ and $Y_{1}^{\prime}$, it is on the average better to adopt $L M_{2}$ than $L M_{3}$ even though the extremes under $L M_{2}$ are a bit larger than under $L M_{3}$.

Extensions of Model. At this point a natural question is that of the extent to which the above analysis would hold in more complex models. Until more complicated models are constructed and analyzed mathematically, there is no way of being certain. But it is possible to make educated guesses on the effects of adding more goals and more policy instruments, and of relaxing the rigid price assumption.

Additional goals may be added to the model if they are specified in terms of "closer is better" rather than in terms of a fixed target that must be met. For example, it would not be mathematically difficult to add an interest rate goal to the model analyzed above, if deviations from a target interest rate were permitted but were treated as being increasingly harmful. On the other hand, it is clear that if there were a fixed-interest target, then the only possible policy would be to peg the interest rate, and income stabilization would not be possible with monetary policy alone.

The addition of fiscal policy instruments affects the results in two major ways. First, the existence of income taxes and of government expenditures inversely related to income (for example, unemployment benefits) provides automatic stabilization. In terms of the model, automatic stabilizers make the IS function steeper than it otherwise would be, thus reducing the impact of monetary disturbances, and reduce the variance of expenditures disturbances in the reduced-form equation for income. This effect would be shown in Figure 6 by drawing $I S_{1}$ so that it cuts $L M_{2}$ to the right of $Y_{1}^{\prime}$ and drawing $I S_{2}$ so that it cuts $L M_{2}$ to the left of $Y_{2}^{\prime}$.

The second major impact of adding fiscal policy instruments occurs if both income and the interest rate are goals. Horizontal shifts in the IS function that are induced by fiscal policy adjustments, when accompanied by a coordinated mone- tary policy, make it possible to come closer to a desired interest rate without any sacrifice in income stability. An obvious illustration is provided by the case in which the optimal monetary policy from the point of view of stabilizing income is to set the interest rate as in Figure 5. Fiscal policy can then shift the pair of $I S$ functions, $I S_{1}$ and $I S_{2}$, to the right or left so that the expected value of income is at the full employment level.

If the interest rate is not a goal variable, then fiscal policy actions that shift the IS function without changing its slope do not improve income stabilization over what can be accomplished with monetary policy alone, provided the lags in the effects of monetary policy are no longer than those in the effects of fiscal policy. An exception would be a situation in which reaching full employment with monetary policy alone would require an unattainable interest rate, such as a negative one.

These comments on fiscal policy have been presented in order to clarify the relationship between fiscal and monetary policy. While monetary policymakers may urge fiscal action, for the most part monetary policy must take the fiscal setting as given and adapt monetary policy to this setting. It must then be recognized that an interest rate goal can be pursued only at the cost of sacrificing somewhat the income goal. ${ }^{6}$

All of the analysis so far has taken place within a model in which the price level is fixed in the short run. This assumption may be relaxed by recognizing that increases in money income above the full employment level involve a mixture of real income gains and price inflation. Similarly, reductions in money income below the full employment level involve real income reductions and price deflation (or a slower rate of price inflation). The model used above can be reinterpreted entirely in terms of money income so that departures from what was called above the "full employment" level of income involve a mixture of real income and price changes. Stabi-

\footnotetext{
6 An interest rate goal must be sharply distinguished from the use of the interest rate as a monetary policy instrument. By a goal variable is meant a variable that enters the policy utility function. Income and interest rate goals might be simultaneously pursued by setting the money stock as the policy instrument or by setting the interest rate as the policy instrument.
} 
lizing money income, then, involves a mixture of the two goals of stabilizing real output and of stabilizing the price level.

However, interpreted in this way the structure of the model is deficient because it fails to distinguish between real and nominal interest rates. Price level increases generate inflationary expectations, which in turn generate an outward shift in the IS function. The model may be patched up to some extent by assuming that price changes make up a constant fraction of the deviation of income from its full employment level and assuming further that the expected rate of inflation is a constant multiplied by the actual rate of inflation. Expenditures are then made to depend on the real rate of interest, the difference between the nominal rate of interest and the expected rate of inflation. The result is to make the IS function, when drawn against the nominal interest rate, flatter and to increase the variance of disturbances to the IS function. These elects are more pronounced: (a) the larger is the interest sensitivity of expenditures; (b) the larger is the fraction of price changes in money income changes; and (c) the larger is the effect of price changes on price expectations. The conclusion is that since price flexibility in effect increases the variance of disturbances in the $I S$ function, a money stock policy tends to be favored over an interest rate policy.

\section{EVIDENCE ON THE RELATIVE MAGNITUDES OF REAL AND MONETARY DISTURBANCES}

\section{Nature of Available Evidence}

Little evidence is available that directly tests the relative stability of the expenditure and money demand functions. It is necessary, therefore, to proceed somewhat indirectly. First, simulation of the FR-MIT model ${ }^{7}$ is used to show the probable size of the effect on gross national product (GNP), the GNP deflator, and the unemployment rate of an assumed expenditure disturbance. This evi-

\footnotetext{
${ }^{7}$ For a general description of the model, see de Leeuw and Gramlich
} (1968). dence provides some indication of the extent to which the impact of an expenditure disturbance depends on the choice between the money stock and the Treasury bill rate as monetary policy control variables. This evidence bears only on the question of what happens if an expenditure disturbance occurs, not on the relative stability of the expenditure and money demand functions. However, this approach is useful when combined with intuitive feelings about relative stability.

The second type of evidence, derived from reduced-form studies, is more directly related to the question of relative stability; nevertheless, it is not entirely satisfactory because the studies examined were not designed to answer the question at hand. To supplement these studies by other investigators, there follows a simple test of the stability of the demand for money function.

\section{Impact of an Expenditure Disturbance}

Simulation of the FR-MIT model provides some insight as to how the size of the impact of an expenditure disturbance depends on the choice of the monetary policy instrument. The simulation technique is necessary because the FR-MIT model is nonlinear, making it impossible to obtain an explicit expression for the reduced form. ${ }^{8}$ However, comparison of two sets of simulations provides some interesting results. Except as indicated below, the simulations all used the actual historical values of the model's exogenous variables and all simulations started with 1962-I, a starting date selected arbitrarily.

The first set of five simulations assumes an exogenous money stock that grows by 1 percent per quarter, starting with the actual money stock in 1961-IV as the base. To investigate the impact of a disturbance in an exogenous expenditures variable, the exogenous variable "federal expenditures on defense goods" was set in one simulation at its actual level minus $\$ 10$ billion; in another at actual minus $\$ 5$ billion; and in three further simulations at actual, actual plus $\$ 5$ billion, and actual plus $\$ 10$ billion. This procedure produces

8 In a reduced-form equation, an endogenous (that is, simultaneously determined) variable is expressed as depending only on exogenous and predetermined variables (variables taken as given for the current period). 


\section{Figure 10}

\section{Reduced-Form Parameter Estimates for Federal Defense Expenditures from FR-MIT Model}

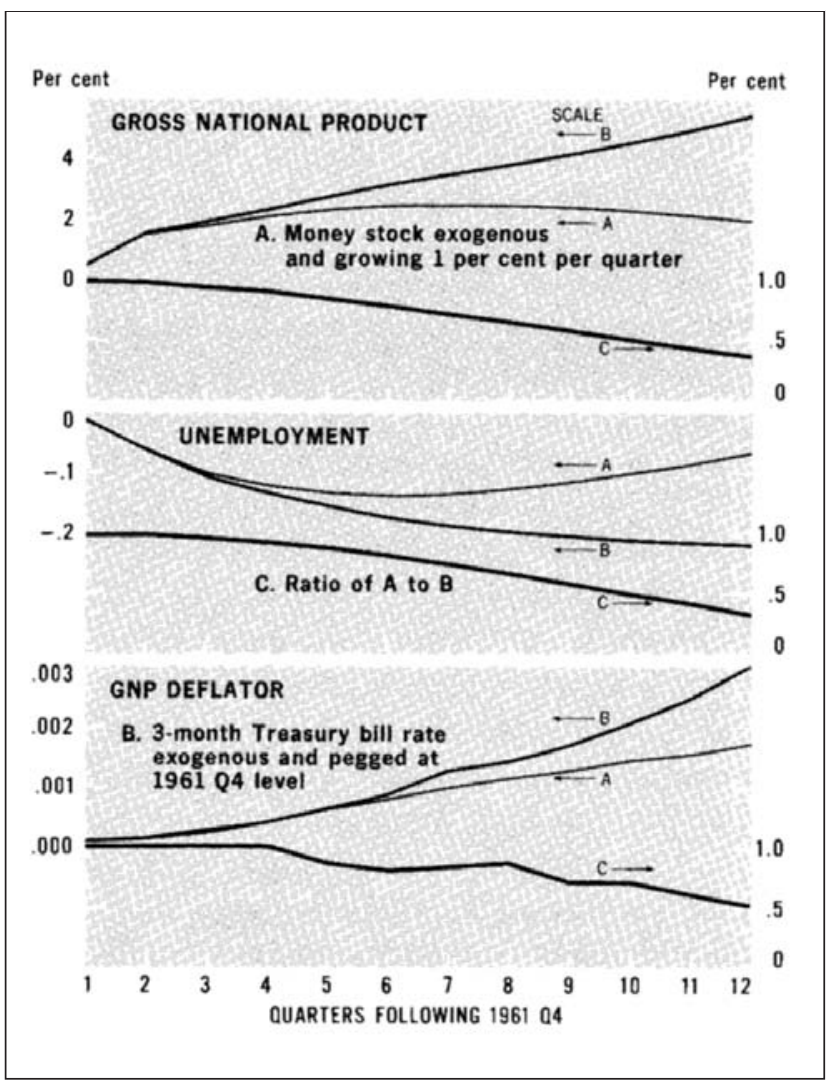

SOURCE: Originally published version, p. 146.

four hypothetical observations on "disturbances" in defense expenditures, of $-10,-5,+5$, and +10 , and the simulation provides four corresponding observations for the change in income (and other endogenous variables). By using income as an example, the change in an endogenous variable in response to a disturbance in defense expenditures is the difference between income simulated by the model when defense expenditures were set at actual historical values and when set at actual plus 10, plus 5, and so forth. The income obtained in the simulations, even when defense expenditures are set at actual levels, is not the same as the actual historical level of income both because the assumed monetary policy differs from the policy actually followed and because of errors in the model itself.

By calculating the ratio of the change in an endogenous variable to the disturbance in defense expenditures for the four observations, four estimates of the linear approximation to the reduced-form parameter, or multiplier, of defense expenditures are obtained, and these four estimates have been averaged to produce a single estimate. Since the effects of a disturbance accumulate over time, the reduced-form parameter estimate has been calculated for the 12 quarters from 1962-I through 1964-IV. Exactly the same procedure has been used for the simulations with a fixed rate for 3-month Treasury bills. Finally, the ratio of the parameter estimates for the reduced forms under the money stock and interest rate policies has been calculated with the parameter estimates from the simulations with the exogenous money stock in the numerator of the ratio.

The reduced-form parameter estimates under the two monetary policies, and the ratios of these estimates, have been plotted in Figure 10 for 12 quarters for the reduced forms for nominal GNP, for the unemployment rate, and for the GNP deflator. The results are striking. A substantial difference appears in the parameters of reduced forms for the fourth quarter following the initial disturbance, and the differences in the parameters become steady thereafter. By the 12th quarter the reduced-form parameters for the money stock policy are only about 40 percent of those for the interest rate policy.

The interpretation of these results is that employment, output, and the price level are far more sensitive to disturbances in defense expenditures under an interest rate policy than under a money stock policy. This conclusion presumably generalizes to expenditures variables other than defense expenditures, but the results would differ in detail because each expenditures variable enters the FR-MIT model in a somewhat different way.

It might be argued that these results suggest that there is no significant difference between interest rate and money stock policies because the reduced-form parameters are essentially identical up to about four quarters. Surely, so this 
argument goes, mistakes could be discovered and onset within four quarters. There are two difficulties with this argument. The first is that the FR-MIT model may overstate the length of the lags and therefore understate the differences in reduced-form parameters for the two policies for the quarters immediately following a disturbance. But the second and more important reason is that it may not be easy to reverse the effects of the disturbance after the disturbance has been discovered. With an interest rate policy, a very large change in the rate might be required to offset the effects appearing after the fourth quarter, and such a change might not be feasible, or at least not desirable in terms of its effects on security markets and on income in the more distant future.

The numerical results reported above depend, of course, on the FR-MIT model, and this model is deficient in a number of respects. But any model in which, other things being equal, investment and other interest-sensitive expenditures decline when interest rates rise will show results in the same direction.

These results may be extended to analyze the significance of errors in forecasting exogenous variables. Consider an explicit expression for the reduced form for income. Let the exogenous variables such as government expenditures, perhaps certain categories of investment, strikes, weather, population growth, and so forth, be $X_{1}, X_{2}, \ldots, X_{n}$, and let the coefficients of these variables be $\alpha_{1}, \alpha_{2}$, $\ldots, \alpha_{n}$ when the interest rate is the policy instrument, and $\lambda_{1}, \lambda_{2}, \ldots, \lambda_{n}$ when the money stock is the instrument. Then the reduced form for income when the interest rate is the instrument is

$$
Y=\alpha_{0}+\alpha_{1} X_{1}+\alpha_{2} X_{2}+\ldots+\alpha_{n} X_{n}+\alpha_{r} r+u
$$

where $\alpha_{r}$ is the coefficient of the interest rate and $u$ is the random disturbance. On the other hand, when the money stock is the instrument, the reduced form is

$$
\text { (2) } Y=\lambda_{0}+\lambda_{1} X_{1}+\lambda_{2} X_{2}+\ldots+\lambda_{n} X_{n}+\lambda_{M} M+v
$$

As discussed in Section II, the disturbance $v_{t}$ may have either a larger or a smaller variance than the disturbance $u_{t}$. One factor tending to make $v_{t}$ smaller than $u_{t}$ is that a money stock policy reduces the impact of expenditures disturbances, but another factor, the introduction into the reduced form of money demand disturbances, tends to make $v_{t}$ larger. The net result of these two factors cannot be determined a priori.

But in formulating policy it is not possible to reason directly from equations 1 and 2 because many of the $X_{i}$ cannot be predicted in advance with perfect accuracy. For scientific purposes ex post it may be possible to say that a change in income was caused by a change in some $X_{i}$; for policy purposes ex ante this scientific knowledge is useless unless the change in $X_{i}$ can be predicted. It is necessary to think of each $X_{i}$ as being composed of a predictable part, $\hat{X}_{i}$, and an unpredictable part, $E_{i}$.

$$
X_{i}=\hat{X}_{i}+E_{i}
$$

For policy purposes the error term in the reduced form includes both the disturbances to the equation and the errors in forecasting exogenous variables. The two types of errors ought to be treated exactly alike in formulating policy. Equations 1 and 2 can then be rewritten as follows:

$$
\begin{aligned}
Y & =\alpha_{0}+\alpha_{i} \hat{X}_{1}+\alpha_{2} \hat{X}_{2}+\ldots+\alpha_{n} \hat{X}_{n} \\
& +\alpha_{r} r+\alpha_{1} E_{1}+\alpha_{2} E_{2}+\ldots+\alpha_{n} E_{n}+u \\
Y & =\lambda_{0}+\lambda_{i} \hat{X}_{1}+\lambda_{2} \hat{X}_{2}+\ldots+\lambda_{n} \hat{X}_{N} \\
& +\lambda_{M} M+\lambda_{1} E_{1}+\lambda_{2} E_{2}+\ldots+\lambda_{n} E_{n}+v
\end{aligned}
$$

For policy purposes the error term in the reducedform equation 3 is the sum of the terms from $\alpha_{1} E_{1 t}$ through $u_{t}$ and in the reduced-form equation 4 the sum of the term $\lambda_{1} E_{1 t}$ through $v_{t}$.

A systematic study of the importance of the $E_{i}$ terms cannot be made because no formal record of errors in forecasting exogenous variables exists insofar as the author knows. However, some insight into the problem may be obtained by listing the variables that must be forecast. Which variables have to be forecast depends, of course, on the model being used. The larger econometric models generally have relatively few exogenous variables that raise forecasting problems because so many variables are explained endogeneously by the model itself. The FR-MIT model has 63 
exogenous variables; some of these are relatively easy to forecast, but others are subject to considerable forecasting error. The latter include such variables as exports, number of mandays idle due to strikes, armed forces, and federal expenditures. Furthermore, this model involves lagged endogenous variables in many equations; hence an inaccurate forecast of GNP next quarter will increase the error in forecasting GNP two quarters into the future, which in turn will lead to errors in forecasting GNP three quarters into the future, and so forth. Errors in forecasting exogenous variables, therefore, produce cumulative errors in forecasting GNP in future quarters.

In simpler models the forecasting problem is more severe. Consider, for example, the opposite extreme from the large econometric model, the single-equation model. Convenient representatives of such models are those spawned in the controversy over the Friedman-Meiselman paper (1963) on the stability of the money/income relationship. The various definitions of exogenous, or "autonomous," spending utilized by the various authors in this controversy are as follows :

a) Friedman-Meiselman definition: Autonomous expenditures consist of the "net private domestic investment plus the government deficit on income and product account plus the net foreign balance" (Friedman and Meiselman, 1963, p. 184).

b) Ando-Modigliani definition: Autonomous expenditures consist of two variables which enter the reduced form with different coefficients. One variable is "property tax portion of indirect business taxes" plus "net interest paid by government" plus "government transfer payment" minus "unemployment insurance benefits" plus "subsidies less current surplus of government enterprises" minus "statistical discrepancy" minus "excess of wage accruals over disbursement." The second variable is "net investment in plant and equipment, and in residential houses" plus "exports" (Ando and Modigliani, 1965a, pp. 695-96, 702).

c) DePrano-Mayer definition: The basic definition is "investment in producers' durable equipment, nonresidential construction, residential construction, federal government expenditures on income and product account, and exports. One variant of this hypothesis subtracts capital consumption estimates, and the other does not" (DePrano and Mayer, 1965a, p. 739). DePrano and Mayer also tested 18 other definitions of autonomous expenditures (DePrano and Mayer, 1965a, pp. 739-40).

d)Hester definition: Autonomous expenditures consist of the "sum of government expenditure, net private domestic investment, and the trade balance" (Hester, 1964a, p. 366). Hester also experimented with three other definitions involving alternative treatments of imports, capital consumption allowances, and inventory investment (Hester, 1964a, pp. 366-67).

To a considerable extent the diversity in these definitions is misleading because except for the Friedman-Meiselman definition all the definitions are in fact rather similar. But whichever definition is used, it is impossible to escape the feeling that inaccurate forecasting of exogenous variables is likely to be a major source of uncertainty. And while this discussion has taken place within the context of formal models, exactly the same problem plagues judgmental forecasting. Every forecasting method can be viewed as starting from forecasts of "input," or exogenous, variables and then proceeding to judge the implications of these inputs for GNP and other dependent, or endogenous, variables.

Regardless of what type of model is used, it appears that for the foreseeable future it will be necessary to forecast exogenous variables that simply cannot be forecast accurately by using present methods. As a result, it seems very likely that the error term including forecast errors has a far smaller variance in equation 4 than in equation 3. Indeed, it might be argued that as a source of uncertainty the $E_{i}$ terms are far more important than the $u$ or $v$ terms, and therefore that the smaller size of the $\lambda_{i}$ parameters as compared to the $\alpha_{i}$ parameters is of great importance. If the parameter estimates from the FR-MIT model are accepted, the standard deviation of the total ran- 
dom term relevant for policy (that is, including errors in forecasting exogenous variables) would be over twice as large under an interest rate policy as under a money stock policy. If this argument is correct, shifting from the current policy of emphasizing interest rates to one of controlling the money stock might cut average errors in half, where errors are measured in terms of the deviations of employment, output, and price level from target levels for these variables.

\section{Evidence from Reduced-Form Equations}

Additional insight into the relative sizes of disturbances under interest rate and money stock policies may be obtained by examining the controversy generated by the Friedman-Meiselman paper on the stability of the money/income relationship (Friedman and Meiselman, 1963). In this paper equations almost the same as equations 1 and 2 above were estimated. The equation corresponding to equation 1 differs in that the exogenous variables were assumed to consist only of a single autonomous spending variable, as defined above. The equation corresponding to equation 2 has the same disability for our purposes, but it also did not include an interest rate as a variable.

Before examining the implications of the Friedman-Meiselman findings for this study, it should be noted that their approach was sharply criticized in papers by Donald D. Hester (1964a), Albert Ando and Franco Modigliani (1965a), and Michael DePrano and Thomas Mayer (1965a). These critics particularly attacked the FriedmanMeiselman definition of autonomous expenditures, and proposed and tested the alternative definitions listed above. However, they also attacked the single-equation approach and recommended the use of large models instead.

The tests of alternative equations must be regarded as inconclusive in terms of which variable- the money stock or autonomous spendingis more closely related to the level of income. ${ }^{9}$

\footnotetext{
9 For reasons that need not be explained here, most of this controversy was conducted in terms of equations with consumption rather than GNP as the dependent variable. In the FriedmanMeiselman study, however, results are reported for equations with GNP (Friedman and Meiselman, 1963, p. 227). Such results are also reported in Andersen and Jordan (1968, p. 17).
}

Both approaches achieve values for $R^{2}$ of 0.98 or 0.99 so that the unexplained variance is very small in both cases. It seems very unlikely that the addition of an interest rate variable to the equations by using autonomous expenditures as the explanatory variable, which addition would make the equations correspond to equation 1 above, would make any substantial difference.

From this evidence it appears that ex post explanations of the level of income are about as accurate by using autonomous expenditures alone as are those by using money stock alone. But given the inaccuracies in forecasting autonomous expenditures, it must be concluded that ex ante explanations by using the money stock are substantially more accurate than those with forecasts of autonomous expenditures. From this evidence, the total random term in equation 4 appears to have a substantially smaller variance than the total random term in equation 3.

For the reasons mentioned by the FriedmanMeiselman critics, evidence from single-equation studies cannot be considered definitive. But neither can the evidence be ignored, especially in light of the difficulties encountered in the construction and the use of large econometric models such as the FR-MIT model.

\section{Evidence on Stability of Demand for Money Function}

One of the shortcomings of the single-equation studies discussed above is that their authors paid too little attention to the stability of regression coefficients over time. Consider the following statement by Friedman and Meiselman:

\section{The income velocity of circulation of money is consistently and decidedly stabler than the investment multiplier except only during the early years of the Great Depression after 1929. There is throughout, including those years, a close and consistent relation between the stock of money and consumption or income, and between year-to-year changes in the stock of money and in consumption or income (Friedman and Meiselman, 1963, p. 186).}

This conclusion is based on correlation coefficients between money and income (or consump- 


\section{Figure 11}

\section{Velocity and Interest Rate Regressions (regressions fitted to quarterly data, 1947-60)}

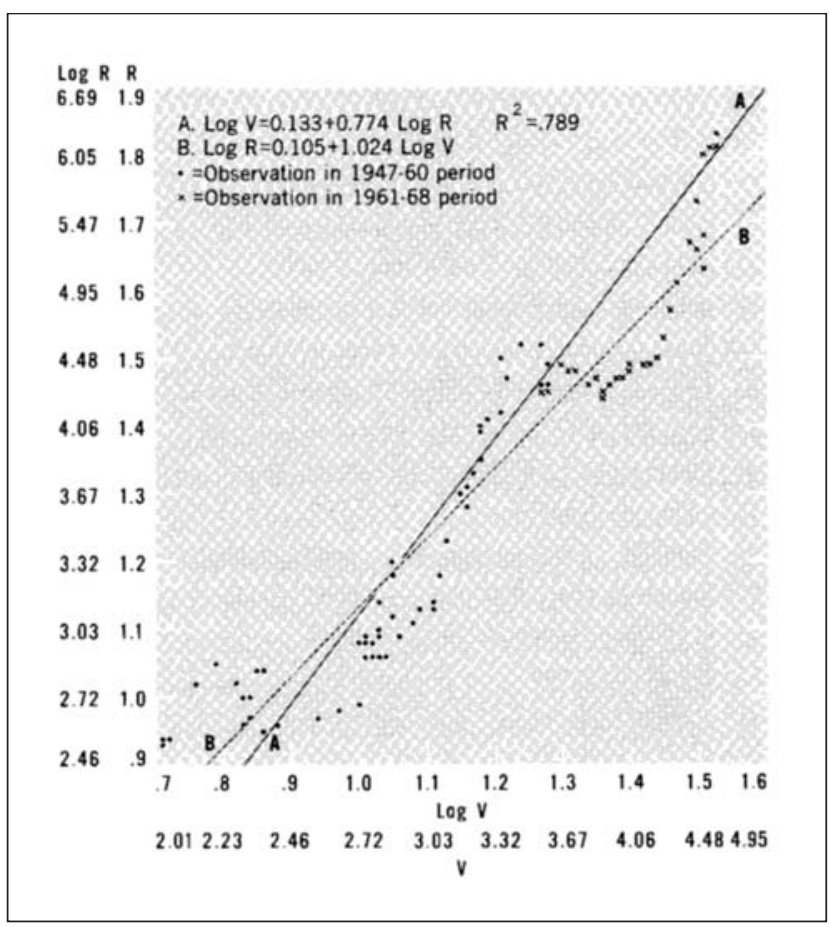

SOURCE: Originally published version, p. 150.

tion), but what is relevant for policy is the regression coefficient, which determines how much income will change for a given change in the money stock. In the Friedman-Meiselman study, a table (Friedman and Meiselman, 1963, p. 227) reports the regression coefficient for income on money as being 1.469 for annual data 1897-1958. However, the same table reports regression coefficients for 12 subperiods, some of which are overlapping, ranging from 1.092 to 2.399 .

With a few exceptions, most economists agree that velocity changes can be explained in part by interest rate changes. ${ }^{10}$ Thus, variability in the regression coefficients when income is regressed on money is not evidence of the instability of the demand for money function. To obtain

${ }^{10}$ For a convenient review of evidence on this subject, see Laidler (1969). some evidence on the stability of this function, the following simple procedure was used. Quarterly data were collected on the money stock, GNP, and Aaa corporate bond yields for 1947 through 1968. A demand for money function was fitted by regressing the log of the interest rate on the log of velocity, and vice versa. The regressions were run for the four periods, 1947 through 1960, 1947 through 1962, 1947 through 1964, and 1947 through 1966. The results inside each estimation period were then compared with the results outside the estimation period.

The results of this process for the 1947-60 estimation period are shown in Figure 11. The observations for 1947 through 1960 are represented by dots, and the observations for 1961 through 1968 by X's. The two least-squares regressions-log interest rate on log velocity and vice versa-fitted for the 1947-60 period have been drawn. From Figure 11 it appears that the relationship since 1960 has been quite similar to the one prior to 1960.

Table 1 presents the results of applying a standard statistical test to the regression and postregression periods to determine whether the demand for money function was stable. To understand this table, refer first to section A of the table, and to the 1947-60 estimation period. Section A reports results from regressing the log of velocity on the log of the Aaa corporate bond rate, and the first row refers to the regression for 1947 through 1960. The square of the regression's standard error of estimate is 0.00517 with 54 degrees of freedom. There were 32 quarters in the postregression period 1961 through 1968, and for this period the mean-square error of velocity from the velocity predicted by the regression is 0.00836 . The ratio of the mean-square errors from regression outside to those inside the estimation period is given in the column labeled " $F$." Since the ratio of two mean squares has the $F$ distribution under the hypothesis that both mean squares were produced by the same process, an $F$ test may be used to test whether the demand for money function has been stable. If the function has been stable, then errors from regression outside the period of estimation 


\section{Table 1}

\section{Tests of the Stability of the Demand for Money Function by Using Quarterly Data}

\begin{tabular}{|c|c|c|c|c|c|c|}
\hline \multirow[b]{2}{*}{ Estimation period } & \multicolumn{2}{|c|}{ Regression } & \multicolumn{2}{|c|}{ Progression } & \multirow[b]{2}{*}{$\boldsymbol{F}$} & \multirow[b]{2}{*}{ Significance level } \\
\hline & $(\mathrm{SEE})^{2}$ & d.f. & MSE & d.f. & & \\
\hline \multicolumn{7}{|c|}{ A. Log velocity regressed on log Aaa corporate bond yield } \\
\hline $1947-60$ & .00517 & 54 & .00836 & 32 & 1.62 & .10 \\
\hline $1947-62$ & .00484 & 62 & .00746 & 24 & 1.54 & .10 \\
\hline $1947-64$ & .00509 & 70 & .00587 & 16 & 1.15 & $>.25$ \\
\hline $1947-66$ & .00502 & 78 & .00986 & 8 & 1.96 & .10 \\
\hline \multicolumn{7}{|c|}{ B. Log Aaa corporate bond yield regressed on log velocity } \\
\hline $1947-60$ & .00684 & 54 & .00589 & 32 & $1.16^{*}$ & $>.25$ \\
\hline $1947-62$ & .00614 & 62 & .00723 & 24 & 1.18 & $>.25$ \\
\hline $1947-64$ & .00570 & 70 & .01162 & 16 & 2.04 & .025 \\
\hline $1947-66$ & .00537 & 78 & .02192 & 8 & 4.08 & .005 \\
\hline
\end{tabular}

should be, on the average, the same size as the errors inside the period of estimation. For the 1947-60 regression being discussed, $F=1.62$ and is significant at the 10 percent level but not at the 5 percent level.

Looking at Table 1 as a whole it can be seen that, for three of the regressions, the errors outside the period of estimation are not statistically significantly larger than those inside the period of estimation. Indeed, for the bond rate regression for the 1947-60 period, the errors outside the period of estimation were actually smaller, on the average, than those inside the period of estimation. Overall, however, these results taken at face value cast some doubt on the stability of the demand for money function.

However, there is reason to believe that there are problems in applying the $F$ test in this situation. The reason is that the residuals from regression exhibit a very high positive serial correlation as indicated by Durbin-Watson test statistics of around 0.15 for all of the regressions. What this means is that the effective number of degrees of freedom is actually less than indicated in the table, and with fewer degrees of freedom the $F$ ratios computed have less statistical significance than the significance levels reported in the table. The only way around this problem is to run a more complex regression that removes the serial correlation of the residuals, but there is no general agreement among economists as to exactly what variables belong in such a regression. The virtue of the simple regressions of velocity on an interest rate and vice versa is that this form has been used successfully by many investigators starting in 1954 (Latané, 1954).

The appropriate conclusion to be drawn from this evidence would seem to be that the relationship between velocity and the Aaa corporate bond rate is too close and too stable to be ignored, but not close enough and stable enough to eliminate all doubts. However, the question is not whether an ironclad case for a money stock policy exists but rather whether the evidence taken as a whole argues for the adoption of such a policy. While there is certainly room for differing interpretations of Figure 11 and Table 1, and of the other evidence examined above, on the whole all of these results seem to point in the same direction. It appears that the money stock rather than interest rates should be used as the monetary policy control variable. 


\section{A MONETARY RULE FOR GUIDING POLICY}

\section{Rationale for a Rule-of-Thumb}

The purpose of this section is to develop a rule-of-thumb to guide policy. Such a rule-not meant to be followed slavishly-would incorporate advice in as systematic a way as possible. The rule proposed here is based upon the theory and evidence in Sections II and III and upon a close examination of post-accord experience.

Individual policymakers inevitably use informal rules-of-thumb in making decisions. Like everyone else, policymakers develop certain standard ways of reacting to standard situations. These standard reactions are not, of course, unchanging over time, but are adjusted and developed according to experience and new theoretical ideas. If there were no standard reactions to standard situations, behavior would have to be regarded as completely random and unpredictable. The word "capricious" is often, and not unfairly, used to describe such unpredictable behavior.

There are several difficulties with relying on unspecified rules-of-thumb. For one thing, the rules may simply be wrong. But an even more important factor, because formally specified rules may also be wrong, is that the use of unspecified rules allows little opportunity for cumulative improvements over time. A policymaker may have an extremely good operating rule in his head and excellent intuition as to the application of the rule but unless this rule can be written down there is little chance that it can be passed on to subsequent generations of policymakers.

An explicit operating rule provides a way of incorporating the lessons of the past into current policy. For example, it is generally felt that monetary policy was too expansive following the imposition of the tax surcharge in 1968. Unless the lesson of this experience is incorporated into an operating rule, it may not be remembered in 1975 or 1980 . How many people now remember the overly tight policy in late 1959 and early 1960 that was a result of miscalculating the effects of the long steel strike in 1959? Since the FOMC membership changes over time, many of the cur- rent members will not have learned firsthand the lesson from a policy mistake or a policy success 10 years ago. If the FOMC member is not an economist, he may not even be aware of the 10-yearold lesson.

It is for these reasons that an attempt is made in this section to develop a practical policy rule that incorporates the lessons from past experience. The rule is not offered as one to be followed to the last decimal place or as one that is good for all time. Rather, it is offered as a guide-or as a benchmark—against which current policy may be judged.

A rule may take the form of a formal model that specifies what actions should be taken to achieve the goals decided upon by the policymakers. Such a model would provide forecasts of goal variables, such as GNP, conditional on the policy actions taken. The structure of the model and the estimates of its parameters would, of course, be derived from past data and in that sense the model would incorporate the lessons of the past.

But in spite of advances in modelbuilding and forecasting, it is clear that forecasts are still quite inaccurate on the average. In a study of the accuracy of forecasts by several hundred forecasters between 1953 and 1963, Zarnowitz concluded that the mean absolute forecast error was about 40 percent of the average year-to-year change in GNP (Zarnowitz, 1967, p. 4). He also reported, "there is no evidence that forecasters' performance improved steadily over the period covered by the data" (Zarnowitz, 1967, p. 5).

Not only are forecasts several quarters ahead inaccurate but also there is considerable uncertainty at, and after, the occurrence of businesscycle turning points as to whether a turning point has actually occurred. In a study of FOMC recognition of turning points for the period 1947-60, Hinshaw concluded that (Fels and Hinshaw, 1968, p. 122):

The beginning data of the Committee's recognition pattern varied from one to nine months before the cyclical turn...On the other hand, the ending of the recognition pattern varied from one to seven months after the turn...With 
the exception of the 1948 peak, the Committee was certain of a turning point within six months after the NBER date of the turn. At the date of the turn, the estimated probability was generally below 50; it reached the vicinity of 50 about two months after the turn.

This recognition record, which is as good as that in 10 widely circulated publications whose forecasts were also studied in (Friedman and Meiselman, 1963) casts further doubt on the value of placing great reliance on the forecasts. ${ }^{11}$

Given the accuracy of forecasts at the current state of knowledge, ${ }^{12}$ it seems likely that for some time to come forecasts will be used primarily to supplement a policy-decisionmaking process that consists largely of reactions to current developments. Only gradually will policymakers place greater reliance on formal forecasting models. ${ }^{13}$ While a considerable amount of work is being done on such models, essentially no attention is being paid to careful specification of how policy should react to current developments. While sophisticated models will no doubt in time be developed into highly useful policy tools, it appears that in the meantime relatively simple approaches may yield substantial improvements in policy. Given that knowledge accumulates rather slowly, it can be expected that carefully specified but simple methods will be successful before large-scale models will lie. Careful specification of policy responses to current developments is but a small step beyond intuitive policy responses to current developments. This step surely represents a logical evolution of the policyformation process.

\footnotetext{
${ }^{11}$ For further analysis of forecasting accuracy, see Mincer (1969).

12 The accuracy of forecasts may now be better than in the periods examined in the studies cited above. But without a number of years of data there would be no way of knowing whether forecasts have improved, and so forecasts must in any case be assumed to be subject to a wide margin of error at the present time.

${ }^{13}$ It may be objected that great reliance is already placed on forecasts, at least on judgmental forecasts. However, these forecasts typically involve a large element of extrapolation of current developments. It seems fair to say that in most cases in which conditions forecast a number of quarters ahead differ markedly from current conditions, policy has followed the dictates of current conditions rather than of the forecasts.
}

\section{Post-Accord Monetary Policy}

That an operating guideline is needed can be seen from the experience since the TreasuryFederal Reserve accord. In order that this experience may be understood better, subperiods were defined in terms of "stable," "easing," or "firming" policy as determined from the minutes of the Federal Open Market Committee. The minutes used are those published in the Annual Reports of the Board of Governors of the Federal Reserve System for 1950 to 1968. The definitions of "stable," "easing," and "firming" periods are necessarily subjective as are the determinations of dates when policy changed. ${ }^{14}$ The dating of policy changes was based primarily on the FOMC minutes, although the dates of changes in the discount rate and in reserve requirements were used to supplement the minutes. "Stable" periods are those in which the policy directive was unchanged except for relatively minor wording changes. In some cases the directive was essentially unchanged although the minutes reflected the belief that policy might have to be changed in the near future. While the Manager of the System Open Market Account might change policy somewhat as a result of such discussions, the unchanged directive was taken at face value in defining policy turning points.

More difficult problems of interpretation were raised by such directives as "unchanged policy, but err on the side of ease," or "resolve doubts on the side of ease." Such statements were used to help in defining several periods during which policy was progressively eased (or tightened). For example, in one meeting the directive might call for easier policy, the next meeting might call for unchanged policy but with doubts to be resolved on the side of ease, and a third meeting might call for further ease. These three meetings would then be taken together as defining an

\footnotetext{
${ }^{14}$ The author was greatly assisted in these judgments by Joan Walton of the Special Studies Section of the Board's Division of Research and Statistics. Miss Walton, who is not an economist, carefully read the minutes of the entire period and in a large table recorded the principal items that seemed important at each FOMC meeting. Having a noneconomist read the minutes tempered the inevitable tendency for an economist to read either too much or too little into the minutes. However, the final interpretation of the minutes rested with the author.
} 
"easing" period. However, unless accompanied by other FOMC meetings clearly calling for a policy change, statements such as those calling for an "unchanged policy with doubts resolved on the side of ease" were interpreted as not calling for a policy change.

Some important monthly economic time series for the post-accord period are plotted in Figure 12. The heavy vertical lines represent periods of "stable," "easing," and "firming” policy as indicated by "S," "E," and "F" at the bottom of the figure. Except for the unemployment rate, the average of each series for each policy period has been plotted as a horizontal line.

The two features of the post-accord experience are especially noteworthy. First, decisions to change policy have been taken about as close to the time when, in retrospect, policy changes were needed as could be expected in the light of existing knowledge. ${ }^{15}$ There have been mistakes in timing, but the overall record is impressive. The second major feature of this period is that policy actions, as opposed to policy decisions, have been in the correct direction if policy actions are defined by either free reserves or interest rates, but not if policy actions are defined in terms of either the money stock or bank credit.

To examine the timing question in more detail, a useful comparison is that between business cycle turning points (as defined by the National Bureau of Economic Research) and decisions to change policy. The post-accord period begins at a time when the U.S. economy was beset by inflation stemming from the war in Korea. the dates of the principal changes in policy and of the business cycle peaks and troughs are listed in Table 2. The policy dates are those that define the beginning of the "stable," "easing," and "firming” periods indicated in Figure 12.

The decision to ease policy was made prior to the business cycle peaks of July 1953 and May 1960. The decision in 1957 was made in the fourth month following the cycle peak in July, but as can be seen from Figure 12, the unemployment rate had not risen very much through October. Given

${ }^{15}$ For additional views on the timing of Federal Reserve decisions, see Brunner and Meltzer (1964) and Fels and Hinshaw (1968). the amount of uncertainty always present in interpreting business conditions, this lag must be considered to be well within the margin of error to be expected for stabilization policy. However, the easing policy decision in 1968 was clearly a mistake in retrospect but not in prospect given the expectations held by the majority of economists that the tax increase would significantly temper the economic boom.

Firming policy decisions were also generally well timed. Following the 1953-54 recession, decisions to firm policy in small steps were taken from December 1954 to September 1955, as unemployment declined to about 4 percent of the labor force. During the recovery period after the 1957-58 recession, firming decisions were taken from July 1958 to May 1959. There was also a series of firming decisions taken from the end of 1961 to 1966. Especially noteworthy are those taken from December 1965 to August 1966, in response to the beginning of inflation associated with the escalation of military activity in Vietnam. The easing policy decisions taken in late 1966 and early 1967 were fully appropriate in light of the economic slack that developed in 1967.

Even from the point of view of those who doubt the importance of fiscal policy, this record of the timing of policy decisions in the post-accord period is remarkably good. The timing record does not suggest that much attention was paid to forecasts, but this lack of attention was perhaps not unfortunate given the accuracy of forecasts during the period. From this point of view, the only real mistake was the easing decision taken in 1968. Of course, those who believe that a steady rate of growth of the money stock is better than any discretionary policy likely to be achieved in practice may read this record as supporting their thesis. But the post-accord record of the timing of policy decisions is certainly encouraging to those who believe that the lags in the effects of policy are short enough, and the effects predictable enough, to make discretionary monetary policy a powerful stabilization tool if only decisions can be made promptly.

While the System's performance in the timing of policy decisions has been commendable, the same cannot be said for the actions taken in 
Table 2

Dates of Principal Monetary Policy Decisions and of Business Cycle Peaks and Troughs

\begin{tabular}{|c|c|c|c|c|}
\hline \multicolumn{2}{|c|}{ Business cycle } & \multicolumn{3}{|c|}{ FOMC policy decisions } \\
\hline \multirow[t]{2}{*}{ Turning point } & \multirow[t]{2}{*}{ Date } & \multirow{2}{*}{$\begin{array}{c}\text { Policy } \\
\text { Accord }\end{array}$} & \multicolumn{2}{|c|}{ Starting date } \\
\hline & & & 1951 & March 1-2 \\
\hline & & Firming & 1952 & September 25 \\
\hline & & Stable & & December 8 \\
\hline \multirow[t]{2}{*}{ Peak } & 1953 July & Easing & 1953 & June 11 \\
\hline & & Stable & & December 15 \\
\hline \multirow[t]{2}{*}{ Trough } & 1954 August & Firming & 1954 & December 11 \\
\hline & & Stable & 1955 & October 4 \\
\hline \multirow[t]{2}{*}{ Peak } & 1957 July & Easing & 1957 & November 12 \\
\hline & & Stable & 1958 & April 15 \\
\hline \multirow[t]{2}{*}{ Trough } & 1958 April & Firming & & July 29 \\
\hline & & Stable & 1959 & June 16 \\
\hline \multirow[t]{2}{*}{ Peak } & 1960 May & Easing & 1960 & March 1 \\
\hline & & Stable & & August 16 \\
\hline \multirow[t]{20}{*}{ Trough } & 1961 February & Firming & 1961 & October 24 \\
\hline & & Stable & & November 14 \\
\hline & & Firming & 1962 & June 19 \\
\hline & & Stable & & July 10 \\
\hline & & Firming & & December 18 \\
\hline & & Stable & 1963 & January 8 \\
\hline & & Firming & & May 7 \\
\hline & & Stable & & August 20 \\
\hline & & Firming & 1964 & August 18 \\
\hline & & Stable & 1965 & March 2 \\
\hline & & Firming & & December 14 \\
\hline & & Stable & 1966 & September 13 \\
\hline & & Easing & & November 1 \\
\hline & & Stable & 1967 & May 2 \\
\hline & & Firming & & November 27 \\
\hline & & Stable & 1968 & April 30 \\
\hline & & Easing & & July 16 \\
\hline & & Stable & & August 13 \\
\hline & & Firming & & December 17 \\
\hline & & Stable & 1969 & April 29 \\
\hline
\end{tabular}


Figure 12

\section{Post-Accord Monetary Policy}

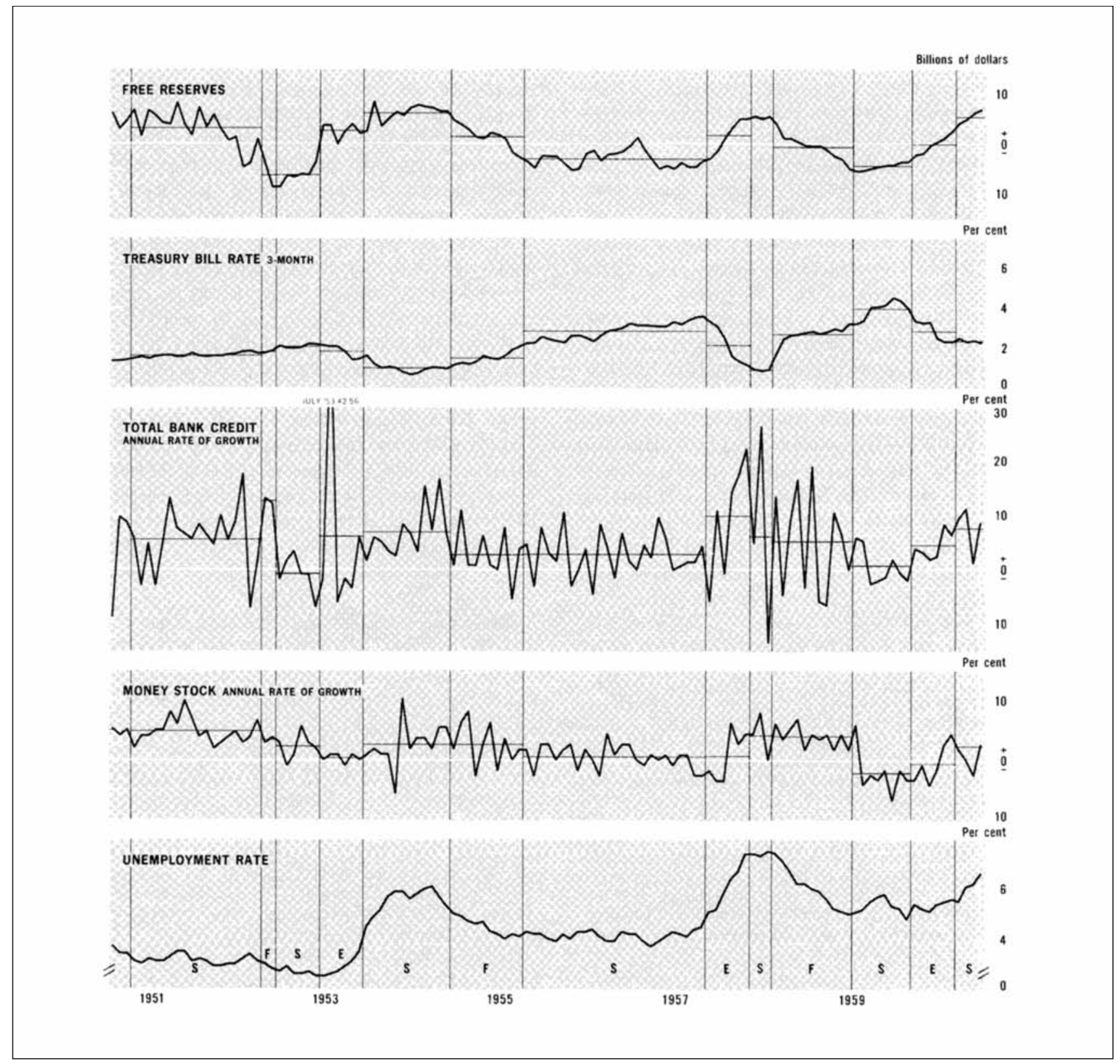

SOURCE: Originally published version, p. 154. 
Figure 12, cont'd

\section{Post-Accord Monetary Policy}

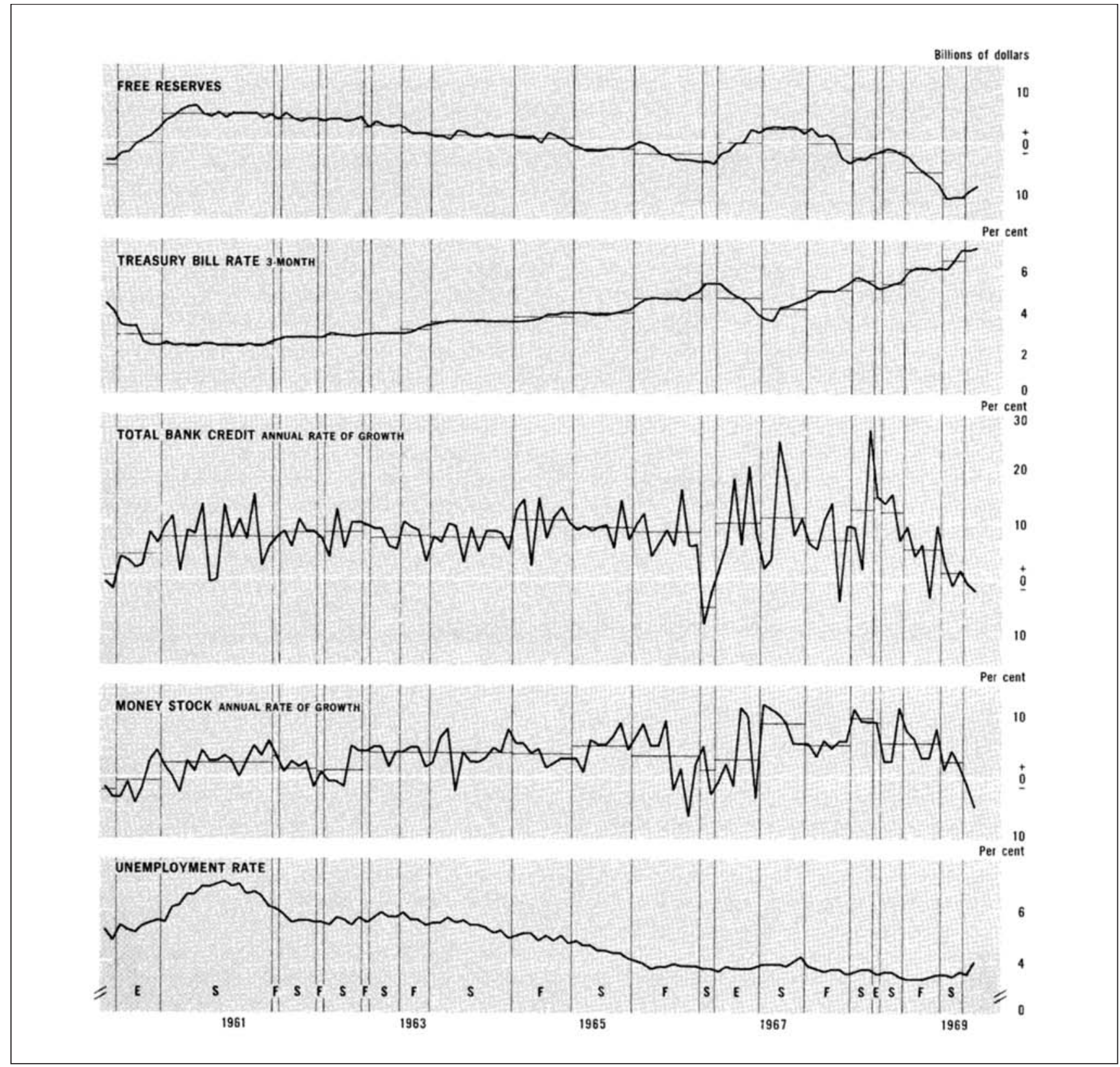

SOURCE: Originally published version, p. 155. 
response to the decisions. In the earlier discussion the purposely vague terms "easing," "firming," and "stable" were used to describe policy decisions. These terms were meant to convey the notions that policymakers wanted, respectively, to accelerate, decelerate, or maintain the pace of economic advance. The question that must now be examined is whether policy actions did in fact tend to accelerate, decelerate, or maintain the level of economic activity.

Policy actions were in accord with policy decisions if these actions are measured by either the 3-month Treasury bill rate or free reserves. The bill rate rose in "firming" periods, fell in "easing" periods, and tended to remain unchanged in "stable" periods. However, there was some tendency for the bill rate to rise in "stable" periods following "firming" periods, and to fall in "stable" periods following "easing" periods, a pattern not inconsistent with the interpretation of policy being offered in this study. Similar comments apply to free reserves.

But the picture is quite different if policy actions are measured by the rate of growth of the money stock. Careful study of Figure 12 will make this point clear. The growth rate declined in response to the "firming" policy decision in late 1952, and again in the "stable" period in early 1953. This behavior was, of course, consistent with the "firming" decision. But the rate of growth declined further following the "easing" decision in June 1953 and remained low until the middle of 1954. The unemployment rate rose rapidly from its low of 2.6 percent at the cycle peak in July 1953 to 6.0 percent in August 1954, the cycle trough; the money stock was at the same level in April 1954, 9 months following the cycle peak and 10 months following the decision to adopt an "easing" policy, as it had been at the peak.

The same pattern that had appeared during the 1953-54 recession appeared again at the time of the 1957-58 recession. The rate of growth of the money stock declined in 1957 prior to the cycle peak. (The Treasury bill rate also rose substantially.) But after the decision to adopt an “easing” policy in November 1957, the growth rate of the money stock declined further. From October 1957 to January 1958, the money stock fell at a 2.9 percent annual rate; from the cycle peak in July to October it had fallen at a 1.5 percent annual rate.

The rate of growth of the money stock increased substantially in February 1958, and it remained at the higher level during the "stable" policy period April to July. There followed a period of "firming" policy decisions from the end of July 1958 to May 1959; however, the average growth rate of the money stock during this period was virtually identical to the average in the preceding "stable" period. But in the "stable" period from June 1959 to February 1960, the rate of growth of money, at -2.2 percent, was much lower than in the preceding "firming" period. This rate of growth of money can hardly be considered appropriate in the light of the fact that except for one month the unemployment rate was continuously above 5 percent. However, the picture was confused by a long steel strike.

The decision to ease policy was taken on March 1, 1960, but the rate of growth of the money stock remained negative until July. The rate of growth of money fell following the "firming" policy decisions of October 1961 and June 1962. In spite of another firming decision in December 1962 the rate of growth then increased, and it continued to rise during the "firming" period in 1963, maintaining the same rate in the following "stable" period. In August 1964, another "firming" decision was taken, and the growth rate trended down during the "firming" period from August 1964 to February 1965.

During the "stable" period from March to November 1965, the Vietnam war heated up. In the second half of 1965 the growth rate of money was 6.1 percent compared with 3.0 percent during the first half. The "firming" policy decision came in December, but the rate of growth of money averaged over 6 percent for the months December through April 1966. At this point monetary growth ceased. In January 1967 the money stock was actually less than in May 1966-there having been no increase in the growth rate in the months immediately following the "easing" decision of November 1, 1966.

The growth rate of money then accelerated during the "stable" period from May through 
October 1967; for the period as a whole growth averaged 8.7 percent. In the following "firming" period November 1967 through April 1968, the rate of growth of the money stock was lower but it was still relatively high at 5.1 percent. The growth rate then rose to 9.6 percent in the "stable" period May through July 1968 and thereafter fell to a little less than 6 percent in the July-November 1968 period following the "easing" decision of July 16 , 1968.

There ensued a "firming" period from December 1968 through April 1969. Although original figures indicated that monetary growth was relatively little during this period, a revision in the money stock series showed that the rate averaged 5.5 percent for the period as a whole. The rate following April was lower, especially in the June-December 1969 period, which saw no net growth in the money stock.

A broadly similar view of the timing of policy actions is obtained from a careful examination of the rate of growth of total bank credit. However, as shown in Figure 12, this series is quite erratic and much more difficult to interpret than the series on the rate of growth of the money stock.

The proper way to interpret these results would seem to be as follows. When interest rates fell in a recession, policy was easier than it would have been if interest rates had not been permitted to fall. But if the money stock was also falling, or growing at a below-average rate, policy was tighter than it would have been had money been growing at its long-run average rate. Similar statements apply to rising interest rates and aboveaverage monetary growth in a boom.

\section{A Monetary Rule}

Given the arguments of Sections I and II on the advantages of controlling the money stock as opposed to interest rates, a logical first step in developing a policy guideline is to examine cases clearly calling for ease or restraint. Consider first a recession. To insure that monetary policy is expansionary, the rule might be that interest rates should fall and the money stock should rise at an above-average rate. This policy avoids two possible errors.
The first is illustrated in Figure 13. If the IS function shifts down from $I S_{1}$ to $I S_{2}$ while the $L M$ function shifts from $L M_{1}$ to $L M_{2}$, the interest rate will fall from $r_{1}$ to $r_{2}$. The shift from $L M_{1}$ to $L M_{2}$ could be caused by a shift in the demand for money with the stock of money unchanged. But this shift could also be caused by a decline in the stock of money, perhaps because of an attempt by policymakers to keep the interest rate from falling too rapidly. However, in terms of income it is clearly better to permit the interest rate to fall to $r_{3}$ by maintaining the stock of money fixed, and better yet to shift the $L M$ function to the right of $L M_{1}$ by increasing the stock of money.

The point is the simple one that monetary policy should not rely simply on a declining interest rate in recession but should also insure that the money stock is growing at an adequate rate. The $L M$ function may still shift to $L M_{2}$ in spite of monetary growth because of an increased demand for money; without the monetary growth, however, this shift in the demand for money would push the $L M$ function to the left of $L M_{2}$ and income would be even lower.

The second type of error avoided by the proposed policy rule is illustrated in Figure 14. Again, it is assumed that the situation is one of recession. With a fixed money stock, an increase in the demand for money will shift the $L M$ function from $L M_{1}$ to $L M_{2}$, tending to reduce income. However, if the interest rate is prevented from rising above $r_{1}$, the increased demand for money is met by an increased supply of money.

Maintaining monetary growth and a declining interest rate in recession insures that the contribution of monetary policy is expansive. Increases in the demand for money, unless accompanied by a falling IS function, are fully offset by preventing increases in the interest rate. The greater the fall in the IS function the smaller the offset to an increased demand for money. However, in no case should a fall in the IS function be permitted to cause a fall in the money stock.

The policy proposed does not, of course, guarantee an expansion of income. No such guarantee is possible because downward shifts in the IS function may exceed any specified shift in the $L M$ function. But more important than theoretical 
Figure 13

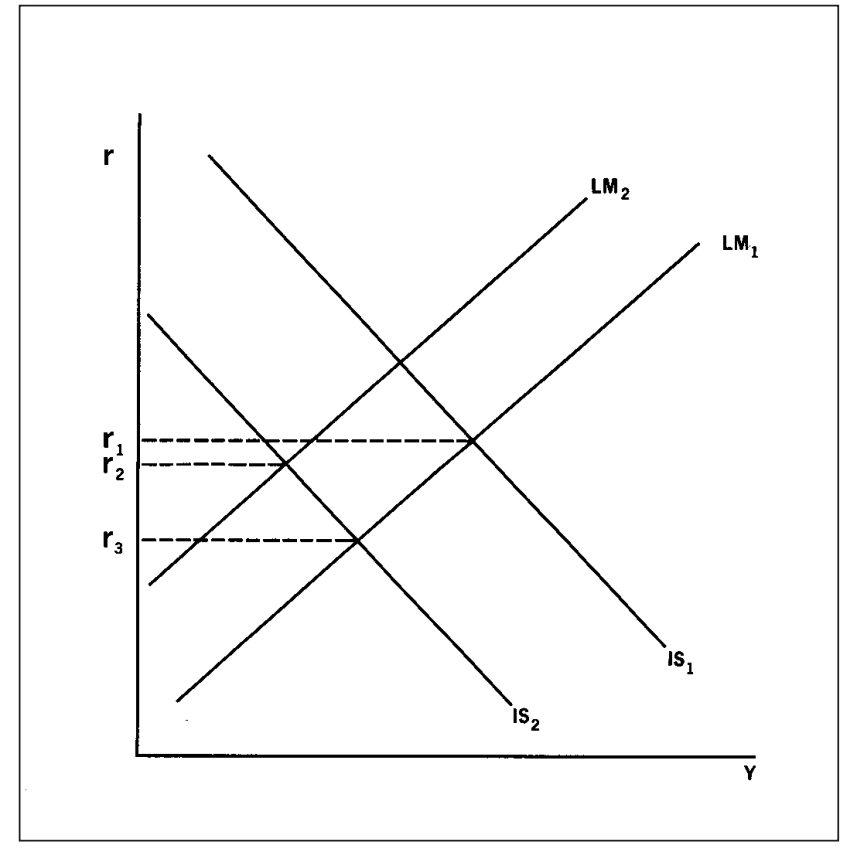

SOURCE: Originally published version, p. 159.

possibilities are empirical probabilities. For all practical purposes the problem is not how to insure expansion in a recession but how to trade off the risks of too much expansion against too little. The discussion of Figures 13 and 14 was entirely in terms of encouraging income expansion, or limiting further declines, in the face of depressing disturbances. But disturbances may be expansionary in a recession, and such disturbances may combine with expansionary policy to create overly rapid recovery from the recession.

Consider again Figure 13, but suppose the initial position is as shown by $I S_{2}$ and $L M_{2}$. If the interest rate is not permitted to rise, a shift to $I S_{1}$ will lead to a large increase in income to the level given by the intersection of $I S_{1}$ with a horizontal $L M$ function drawn at $r_{2}$. This situation can be avoided only if the interest rate is permitted to rise. The natural question is how the interest rate can be permitted to rise within a recession policy of pushing the interest rate down and maintaining above-average monetary growth. The answer is that the recession policy should be followed

\section{Figure 14}

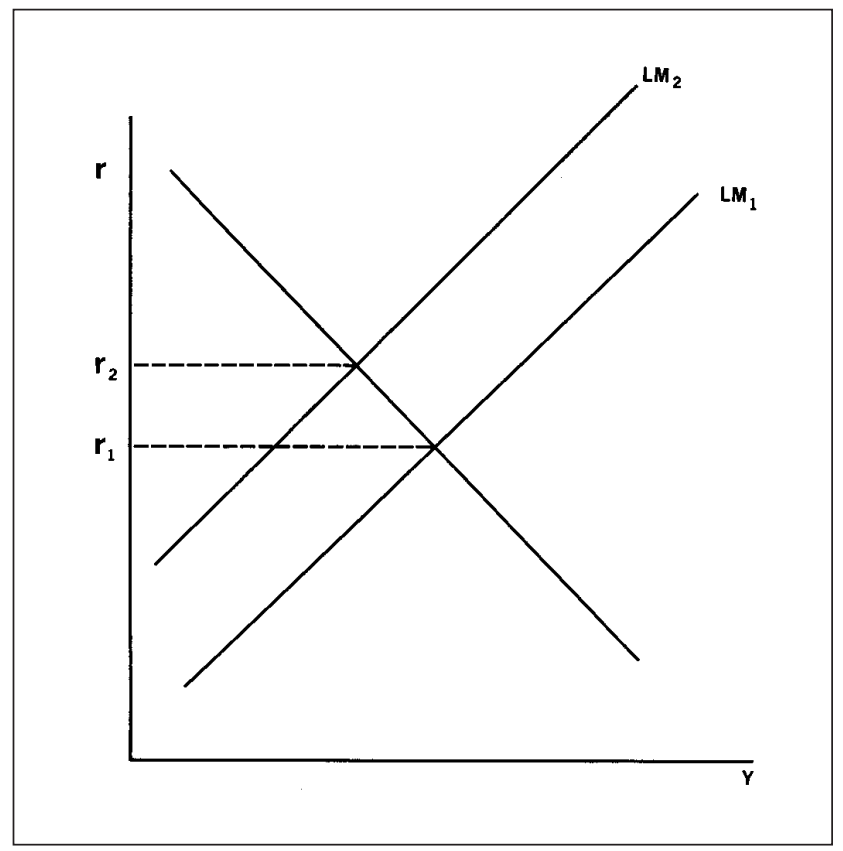

SOURCE: Originally published version, p. 159.

only if the interest rate can be kept from rising with a monetary growth rate below some upper bound.

Exactly the same analysis running in reverse applies to a policy for checking an inflationary boom. In a boom interest rates should rise and monetary growth should be below average. However, there must be a lower limit on monetary growth to avoid an unduly contractionary policy. Having presented the basic ideas behind the formulation of a monetary rule, it is now necessary to become more specific about the rule. After specifying the rule in detail, it will be possible to discuss the considerations behind the specific numbers chosen.

The proposed monetary policy rule-of-thumb is given in Table 3 . The rule assumes that full employment exists when unemployment is in the 4.0 to 4.4 percent range and that monetary growth in the 3 to 5 percent range is consistent with price stability. At full employment the Treasury bill rate may rise or fall, either because of market pressures or because of small adjustments in monetary 


\section{Table 3}

\section{Proposed Monetary Policy Rule-of-Thumb (Percent)}

\begin{tabular}{|c|c|c|}
\hline \multirow[b]{2}{*}{ Unemployment rate previous month } & \multicolumn{2}{|c|}{ Rule for month* } \\
\hline & $\begin{array}{c}\text { Direction of Treasury bill rate } \\
\text { (3-month) }\end{array}$ & $\begin{array}{l}\text { Growth of money stock } \\
\text { (annual rate) }\end{array}$ \\
\hline $0-3.4$ & Rising & $1-3^{+}$ \\
\hline $3.5-3.9$ & Rising & $2-4^{\dagger}$ \\
\hline $4.0-4.4$ & Rising or falling & $3-5$ \\
\hline $4.5-4.9$ & Falling & $4-6^{\ddagger}$ \\
\hline $5.0-5.4$ & Falling & $5-7^{\ddagger}$ \\
\hline $5.5-5.9$ & Falling & $6-8^{\ddagger}$ \\
\hline $6.0-100.0$ & Falling & $6-8$ \\
\hline
\end{tabular}

NOTE: *The 3-month bill rate is to be adjusted in the indicated direction provided that monetary growth is in the indicated range. If the bill rate change cannot be achieved within the monetary growth rate guideline, then the bill rate guideline should be abandoned. ${ }^{+}$If the bill rate the previous month was below the bill rate 3 months prior to that, then the upper and lower limits on monetary growth are both increased by 1 percent. IIf the bill rate the previous month was above the bill rate 3 months prior to that, then the upper and lower limits on monetary growth are both reduced by 1 percent.

policy; however, monetary growth should remain in the 3 to 5 percent range.

When unemployment drops below 4 percent, the rule calls for a restrictive monetary policy. The bill rate should rise and monetary growth should be reduced. If the bill rate and monetary growth guidelines are not compatible, then the monetary guideline should be binding. For example, suppose that unemployment is in the 3.5 to 3.9 percent range. If monetary growth below 2 percent would be required to obtain a rising bill rate, then monetary growth should be 2 percent and the bill rate be permitted to fall. If this situation persists so that the bill rate falls for several months in spite of the low monetary growth, then the limits on monetary growth should be increased as indicated in footnote 2 to Table 3 . The reason for this prescription is that the bill rate on the average turns down 1 month before the peak of the business cycle (Holt, 1962, p. 111). Unemployment, on the other hand, may increase relatively little in the early months following a cycle peak. Tying monetary growth to the bill rate in the way indicated in footnote 2 of Table 3 produces a more timely adjustment of policy than relying on the unemployment rate alone.
The proposed rule calls for a falling bill rate and a relatively higher rate of monetary growth as unemployment rises above the 4.0 to 4.4 percent range. The rule for high unemployment situations calls for adjusting the monetary growth rate downward when the bill rate is consistently rising as indicated by footnote 3 to Table 3 . The reasoning behind this adjustment is exactly parallel to the reasoning above for low unemployment situations.

The proposed monetary rule has the virtues of simplicity and dependence on relatively wellestablished economic doctrine. Because of its simplicity, the basic ideas behind the rule can be explained to the noneconomist. The simplicity of the rule also will make possible relatively easy evaluations of the rule's performance in the future if the rule is followed. With more complicated rules it would be much more difficult to know how to improve the rule in the future because it would be difficult to judge what part of the rule was unsatisfactory. Since, as has been repeatedly emphasized above, the rule is not proposed as being good for all time, it is best to start with a simple rule and then gradually to introduce more variables into the rule as experience accumulates. 
In designing the rule, the attempt was made to base the rule on fairly well-established economic knowledge. There is, of course, a great deal of debate as to just what is and what is not well established. What can be done, and must be done, is to explain as carefully as possible the assumptions upon which the rule is based, with full recognition that other economists may not accept these assumptions.

First, the evidence for the importance of money is impressive. It seems fair to say that very few economists believe today that changes in the stock of money have nothing to do with business fluctuations. Rather, the argument is over the extent to which monetary factors are important. Some no doubt will feel that the 2-percentagepoint ranges on monetary growth specified by the rule are excessively narrow; however, it should be noted that a 4 percent growth rate is double a 2 percent growth rate. Also important is the fact that the rule is meant to serve as a guideline rather than be absolutely binding. Since policy should deviate from the rule if there is good and sufficient reason-such as wartime panic buying - a further element of flexibility exists within the framework of the rule.

The rule is specified in terms of changes in the bill rate and the monetary growth rate, with the monetary growth rate being tied to the unemployment rate and to changes in the bill rate in the recent past. This formulation has been designed to avoid what seem to be the most obvious errors of the past. Over the years the monetary growth rate has been lowest at business cycle peaks and in the early stages of business contractions, and highest at cycle troughs and in the middle stages of business expansions. The highest rate of monetary growth since the Treasury-Federal Reserve accord has been during the inflation associated with escalation of military operations in Vietnam. For purposes of smoothing the business cycle, so far as this author knows, there is no theory propounded by any economist that would call for high monetary growth during inflationary booms and low monetary growth during recessions. Such behavior of the money stock could only be optimal within a theory in which money had little or no effect on business fluctuations and in which other goals such as interest rate stability were important. Being based on the unemployment rate and bill rate changes in the recent past, the proposed monetary rule does not rely on forecasting. Nor does the rule depend on the current and projected stance of fiscal policy. Both of these factors ought to be included in applying the rule by adjusting the rate of growth of the money stock within the rule limits, or even by going outside the limits. But given the accuracy of economic forecasts under present methods, and given the current uncertainty over the size of the impact of fiscal policy (not to mention the hazards in forecasting federal receipts and expenditures), it does not appear that these variables can be systematically incorporated into a rule at the current state of knowledge.

\section{Tests of the Proposed Rule}

Three types of evidence on the value of the rule are examined below. The first approach involves a simple comparison of the rule with the historical record to show that the rule would generally have been more expansionary (contractionary) than actual policy when actual policy—in the light of subsequent economic developments-might be judged to have been too contractionary (expansionary). The second approach examines the cyclical behavior of the estimated residuals from a simple demand for money function to show that it is unlikely that the proposed rule would interact with the disturbances to produce an excessively inflationary or deflationary impact. Both these approaches are deficient because they rely heavily on the historical record, a record that would have been quite different had the rule been followed in the past. To avoid this difficulty, a third approach uses simulation of the FR-MIT model, but the results do not appear very useful because of shortcomings in this model.

An Impressionistic Examination of the Rule. Broadly speaking, the results of comparing the rule with the historical record since the TreasuryFederal Reserve accord in March 1951 are these. The rule would have provided a substantially tighter monetary policy than the actual during the inflationary period from the accord until about September 1952. At that point, actual 
policy as measured both by the rate of growth of the money stock and by the 3-month bill rate became considerably tighter. In the last quarter of 1952, actual policy was in accord with the rule, but thereafter it tightened even further. In the 9 months following the cyclical peak in July 1953, the money stock had a zero rate of growth while the unemployment rate rose from 2.6 percent to 5.9 percent. Under the rule the rate of growth of the money stock would never have gone below 1 percent and would have steadily increased as unemployment rose.

Actual policy became more expansive in the second quarter of 1954, and the cycle trough was reached in August. However, the rule would have been considerably more expansive, and it would have remained more expansive than the actual all through the 1955-56 boom. Inasmuch as the unemployment rate remained near 4.0 percent from May 1955 through August 1957, the rule would have been too inflationary during this period. However, it can be argued that monetary policy was overly restrictive before the cycle peak in July 1957, since in the year prior to the peak the money stock grew only by 0.7 percent. Less subject to dispute is the fact that policy was far too restrictive after the peak; in the 6 months following the peak the money stock fell at an annual rate of 2.2 percent, and at the same time the unemployment rate rose from 4.2 percent to 5.8 percent.

The rule would have been considerably more expansive all during the high unemployment period of 1958-59, and it would have prevented the declines in the money stock in late 1959 and early 1960. At the peak in May 1960 the unemployment rate was 5.1 percent, and the money stock had fallen by 2.1 percent in the previous 12 months. Unlike the periods following peaks in 1954 and 1957, policy became more expansive immediately after the May 1960 peak, although not so expansive as called for by the proposed rule.

From the trough in February 1961 through June 1964, the unemployment rate never declined below 5 percent. Under the rule, policy would have been more expansive than the actual policy followed throughout this period, especially as compared with the March-September 1962 period, during which the money stock fell slightly. Unemployment fell rapidly in 1965 with the Vietnam build-up; the rule would have been more expansive than actual through July 1965 and then less expansive than actual through April 1966. Indeed, in the 9-month period prior to April 1966, with the unemployment rate falling from 4.4 percent to 3.8 percent, monetary growth accelerated to a 6.6 percent annual rate; the proposed rule would have first called for monetary growth in the 3 to 5 percent range, and then in the 2 to 4 percent range starting in February 1966, following the drop in the unemployment rate below 4.0 percent in January. Finally, the negative growth rates of money in the 1966 credit crunch would have been avoided under the rule, as would the high rates of growth in 1967 and 1968.

This impressionistic look at the proposed rule may be supplemented by a simple scoring system for judging when the rule would have been in error. For each month during the sample period it was determined whether the rule would have been more or less expansive than the actual policy, or about the same as the actual policy. The unemployment rate 12 months from the month in question was used to indicate whether or not the policy was correct, with a desired range of unemployment of 4.0 to 4.4 percent. The rule was deemed to have made an error if: (1) the actual policy was in accord with the rule, but unemployment 12 months later was not in the desired range; (2) the rule called for a more expansive policy than the actual, and unemployment 12 months later was below the desired range; and (3) the rule called for a less expansive policy than the actual, and unemployment 12 months later was above the desired range.

Since the latest data used in this analysis were for July 1969, comparison of the rule with actual policy ends July 1968. Starting the sample with 1952, the first full year after the accord, provides a total of 199 months. Based on the criterion described above, the rule would have been in error in 63 months. If the criterion is changed by substituting the unemployment rate 9 months 
ahead instead of 12 months ahead, the rule has 62 errors; using the unemployment rate 6 months ahead yields 59 errors.

Some of these errors are of negligible import. For example, in March 1953 the rule calls for a money growth rate of 2 to 4 percent, but the actual was 1.9 percent. Thus, the rule would have been more expansive than the actual this particular month, a mistake since unemployment was too low and inflation too high during this period. However, the rule would have been less expansive than actual in every one of the preceding 6 months and in all but one of the 6 months following this "mistake." Except for scattered errors such as the one just discussed, most of the rule errors occurred in two separate periods. The first is the 2-year period following the cycle trough in August 1954, during which time the rule would have been too expansive. The second is the last half of 1964 and the first half of 1965, when the rule would have been too expansive in light of the subsequent sharp decline in unemployment.

Unless one has completed a careful examination of the data, there is a tendency to underestimate how rapidly the economy can change. For example, from the cycle peak in July 1953 to the cycle trough 13 months later, the unemployment rate rose by 3.4 percentage points; and from the peak in July 1957 to the trough 9 months later in April 1958, it rose by 3.2 percentage points. Changes in the other direction have tended to be somewhat less rapid, but significant nonetheless. In the year following the trough in August 1954, the unemployment rate declined 2.0 percentage points, and it declined 2.2 percentage points in the year following the trough in April 1958. In January 1965 unemployment was 4.8 percent and the problem was still one of how to reach full employment. A year later the rate was 3.9 percent and the problem was inflation.

Thus, it appears that for the most part the rule would have been superior to policy actually followed. Of course, the rule is not infallible and would have erred on a number of occasions. But in spite of these errors-and it should be recognized that some errors are inevitable no matter what rule or which discretionary policymakers are in charge-the proposed rule has the great virtue of turning policy around promptly as imbalances develop.

Relationship of the Rule to Monetary Disturbances. Since the rule was developed on the basis of the theoretical and empirical analysis of Sections I and II, which emphasized the relative stability of the demand for money, it is appropriate to conduct a systematic examination of the disturbances in the demand for money. It will be recalled that the rule was formulated in such a way as to insure expansionary policy action in a recession and contractionary policy action in a boom. However, it was recognized that disturbances in the expenditure sector and/or in the monetary sector might reinforce policy actions leading to an excessively expansionary or contractionary effect on income. If there were a significant chance of these excessive effects occurring, then the rule proposed would be overly "aggressive" and a rule involving a smaller range of monetary growth rates would be in order.

To provide some evidence of the effect of disturbances in the money demand function, the residuals from the simple velocity function tested in Section II were examined carefully. The technique involved regressing velocity on the Aaa corporate bond rate, and vice versa, for the 1947-68 period and then comparing the residuals with turning points in the business cycle. The reader may make these comparisons visually from Figure 15. At the bottom of this figure cycle peaks and troughs are identified by "P" and "T," respectively.

The residuals from the estimated equations suggest that the demand for money has contractionary disturbances near business cycle peaks and expansionary disturbances near cycle troughs. The residuals have the same turning points for the regression of velocity on the interest rate as for the regression of the interest rate on velocity. The residual peaks occur at or before the cycle peaks, while the residual troughs occur at or after the cycle troughs.

To assess the significance of these endings, consider the following simple view as to the dynamics of monetary elects. In the short run, income is a predetermined variable in the demand for money function. An increase in the money 
Figure 15

\section{Residuals from Velocity Regression Compared with Business-Cycle Turning Points}

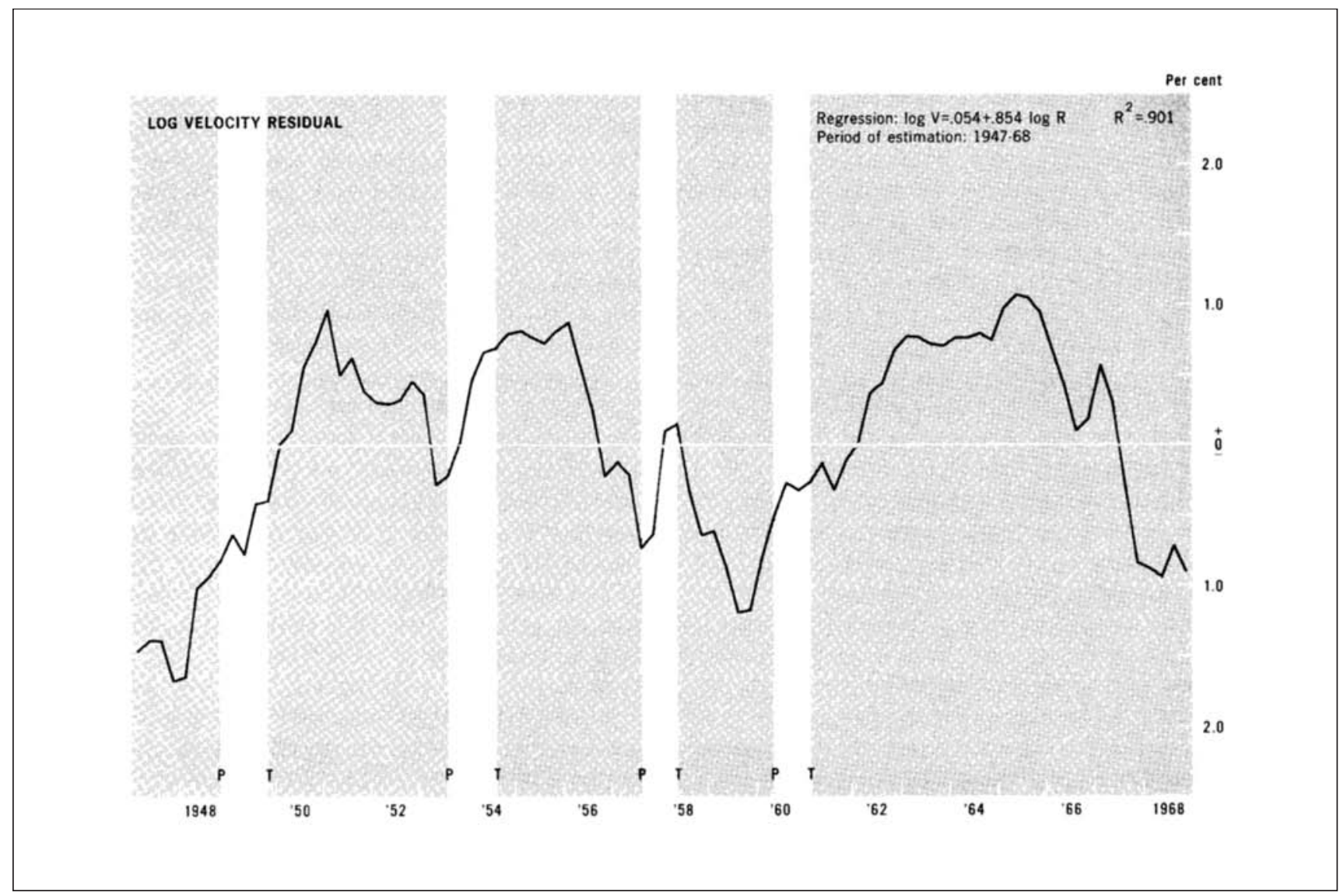

SOURCE: Originally published version, p. 164.

stock makes the interest rate lower than it would be otherwise, and this eventually leads to expansion in investment and income. A downward disturbance in the demand for money function has the same effect.

Given this view of monetary dynamics, Figure 15 suggests the following conclusions. Shifts in the demand for money tend to be contractive in their effect on income in the late stages of a business cycle expansion, implying that a restrictive monetary policy must not be pushed too hard. Then, shortly before the cycle peak, the shifts apparently tend to become expansive. This effect is fortunate since it is only after the cycle peak that rising unemployment would trigger a policy change under the proposed rule. However, there appears to be little danger that the rule would be overly expansionary because after the cycle trough, while policy is still expansionary, contractive shifts in the demand for money occur.

Simulations of the FR-MIT Model. The final technique used to test the proposed monetary rule was to simulate the FR-MIT model under the rule. As explained below, the results are of questionable value but are presented anyway for the sake of completeness and in order not to suppress results unfavorable to the proposed rule.

To simplify the computer programming, the rule used in the simulations is not exactly the same as the one proposed in Table 3 above. The 
Figure 16

\section{Simulations of Unemployment in FR-MIT Model}

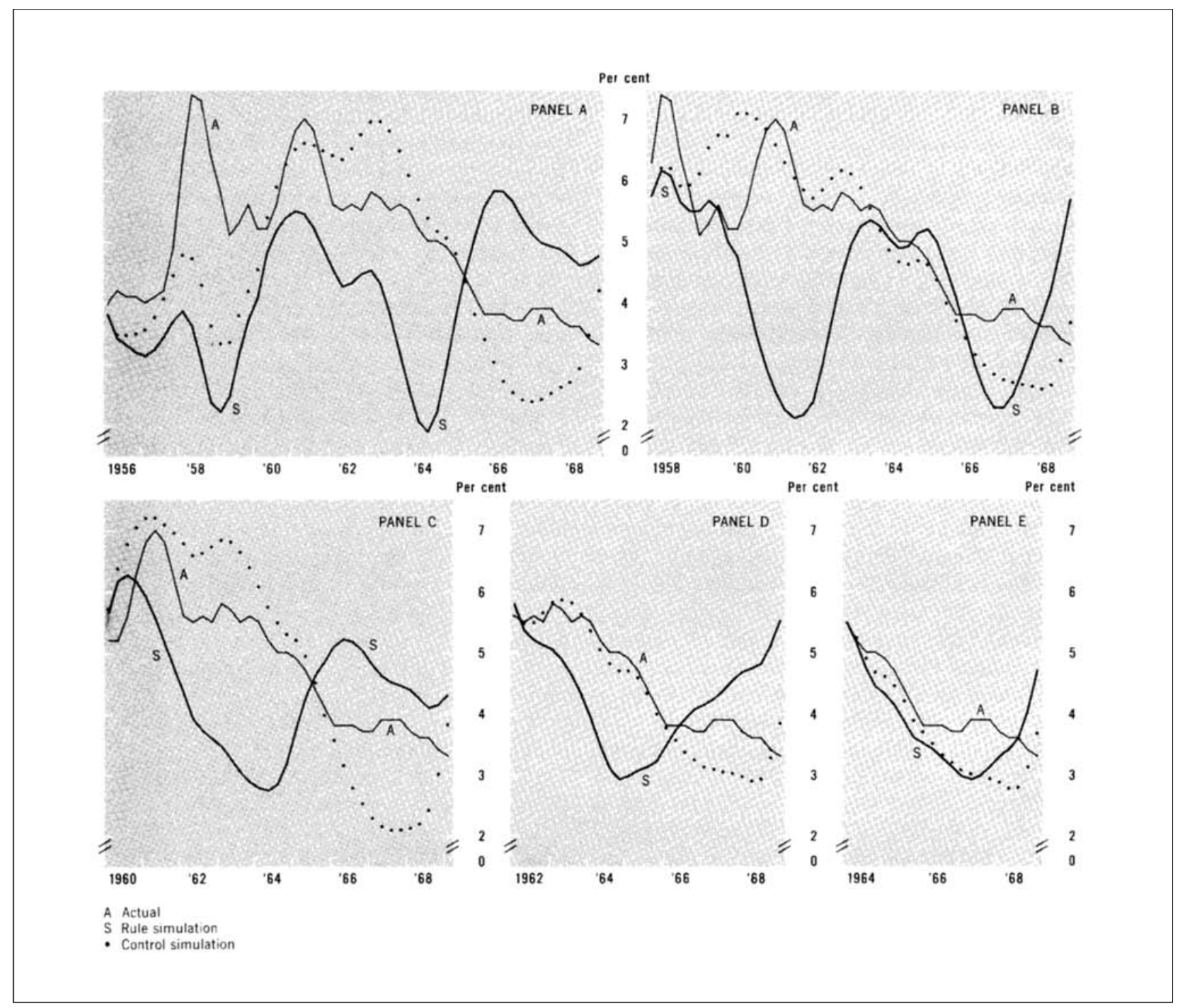

SOURCE: Originally published version, p. 165. 
proposed rule, it will be recalled, involved a bill rate guideline and a money stock guideline. If, for example, the bill rate cannot be pushed up without pushing monetary growth below the lower limit in the money guideline, the proposed rule calls for setting monetary growth at its lower limit. The simulation rule, on the other hand, ignores the bill rate guideline and simply sets the monetary growth rate at the midpoint of the range specified by the proposed rule.

Another difference, and no doubt a more important one, between the proposed rule and the simulation rule is that the simulation rule had to be specified in terms of quarterly data since the FR-MIT model uses quarterly data. In the simulation rule, the growth rate of the money stock depends on the level of unemployment determined by the model in the previous quarter. The growth rate of the money stock was modified by past changes in the bill rate, as in footnotes 2 and 3 to Table 3, except that the relevant bill rate change was in terms of the previous quarter before that. The simulation rule, then, reacts somewhat more slowly to unemployment trends than does the proposed rule.

In order to investigate the importance of the starting point, simulations were run with starting dates in the first quarters of 1956, 1958, 1960, 1962, and 1964. The simulated unemployment rate for the five simulations is shown in the five panels of Figure 16 by the curves marked "S." The actual unemployment rate is shown by the curves marked "A" and control simulations, to be explained below, by the unconnected points.

It is clear from Figure 16 that the simulation rule for money growth produces an unstable unemployment rate. However, because of deficiencies in the model this result is probably not very meaningful. That the model is defective can be seen by comparing unemployment in the control simulations with the actual unemployment. In the control simulations all of the model's exogenous variables, including the money stock, were set at their actual levels. ${ }^{16}$ Even with the exoge-

\footnotetext{
${ }^{16}$ The FR-MIT model was estimated with the money stock as an endogenous variable. There are separate equations for currency and demand deposits, both of which are endogenous, while unborrowed reserves are exogenous. In the simulations the money stock
}

nous variables set at their actual levels, the simulated level of unemployment at times differs from the actual level.

Because of the role of the stochastic disturbances in the model, especially as they feed through lagged endogenous variables, it cannot be expected that control simulations will exactly duplicate the actual results. But the fact that the control simulations differ from the actual by considerable margins over long periods of time strongly suggests that the money rule simulations do not provide much useful information on the properties of the proposed rule.

The simulations are valuable in one respect, however. An examination of Figure 16 strongly suggests that the money rule is interacting with the rest of the model to produce a cycle of 5 to 6 years. Such a cycle is particularly evident in the simulations starting in 1956 and 1958. That the monetary rule has very powerful effects in the model is shown by the simulations beginning in 1960 and 1962. In both simulations unemployment reaches a trough in 1964 and then rises in spite of the 1964-65 tax cuts and the stimulus of spending for military operations in Vietnam starting at the end of 1965.

There is no doubt that the monetary rule is too aggressive within the context of the FR-MIT model. A simulation of a perfectly steady rate of growth of money is shown in Figure 17. The rate of growth in this simulation is 2.76 percent per year, the same as the actual rate of growth over the period 1955-IV through 1969-I. In Figure 17, the curve labeled $S_{2}$ is the simulated unemployment rate with the steady rate of growth of money. The simulated unemployment rate under the monetary rule is shown by $S_{1}$, which is the same as $S$ in panel A of Figure 16. The unconnected points show the same control simulation as shown in panel A of Figure 16.

\footnotetext{
was made exogenous by suppressing the equation that makes demand deposits depend on unborrowed reserves. To simulate the effects of a particular rate of growth of money, the currency equation was retained, but demand deposits were set at whatever level was required to obtain the desired rate of growth of demand deposits plus currency. In the control simulations demand deposits were set at their actual levels, but currency remained an endogenous variable and differed somewhat from actual since simulated GNP differed somewhat from actual GNP.
} 


\section{Figure 17}

\section{Simulations of FR-MIT Model}

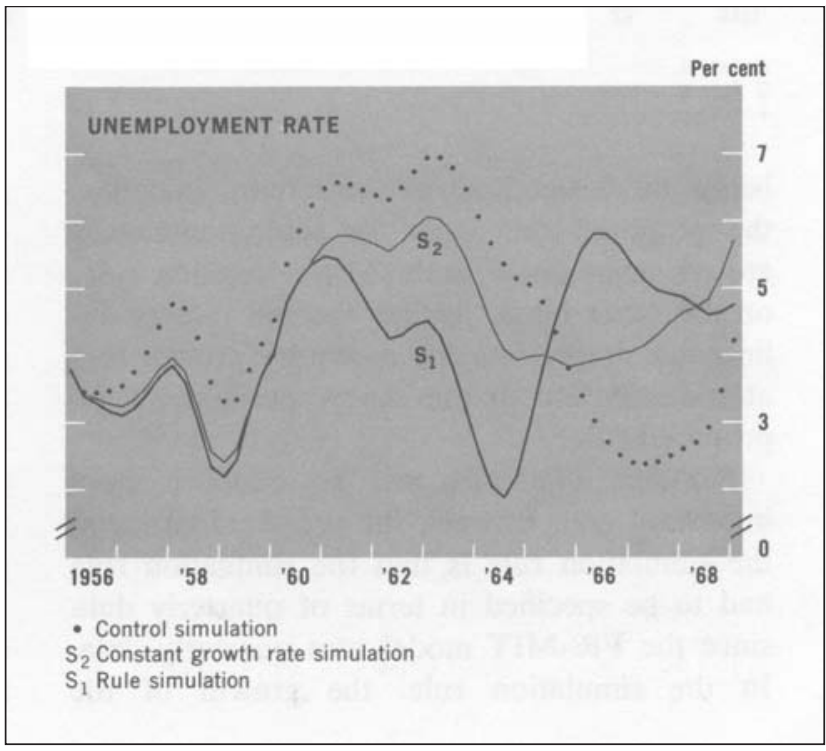

SOURCE: Originally published version, p. 166.

It appears impossible to draw any firm conclusions from the simulations. However, the simulations clearly raise the possibility that the proposed monetary rule may produce economic instability. If anything, the proposed rule is too aggressive, and so policy should probably err on the side of producing growth rates in money closer to a steady 3 to 5 percent rather than farther from the extremes in the proposed rule.

\section{SELECTION AND CONTROL OF A MONETARY AGGREGATE}

\section{Basic Issues}

Up to this point, the analysis has been entirely in terms of optimal control of the money stock. The theoretical analysis has been general enough that no precise definition of the money stock has been required. The empirical work, however, has used the narrow definition of demand deposits adjusted plus currency, for the simple reason that this definition seems to be the most appropriate one.
In principle there is no reason not to look simultaneously at all of the aggregates and, of course, at all other information as well. But in practice, at the present state of knowledge, there simply is no way of knowing how all of these various measures ought to be combined. ${ }^{17}$ Furthermore, the selection of a single aggregate for operating purposes would permit the FOMC to be far more precise in its policy deliberations and in its instructions to the Manager of the Open Market Account. Thus, the best procedure would seem to be to select one aggregate as the policy control variable, and insofar as the state of knowledge permits, to incorporate other information into policy by making appropriate adjustments in the rate of growth of the aggregate selected.

In principle the aggregate singled out as the control variable should be subject to exact determination by the Federal Reserve. The reason is that errors in reaching an aggregate that cannot be precisely controlled may interact with disturbances in the relationships between the aggregate and goal variables such as GNP to produce a suboptimal policy. However, as argued later in this section, this consideration is likely to be quite unimportant in practice for any of the aggregates commonly considered. Therefore, the analysis of which aggregate should be singled out will be conducted under the assumption that all of the various aggregates can be precisely controlled by the Federal Reserve.

\section{Selection of a Monetary Aggregate}

At the outset it must be emphasized that the various aggregates frequently discussed are all highly correlated with one another in the postwar period. This is true for total bank credit, the narrow money stock, the broad money stock (narrow money stock plus time deposits), the bank credit proxy (total member bank deposits), the

\footnotetext{
17 This point is an especially important one since those favoring simple approaches are frequently castigated for ignoring relevant information, and for applying "simplistic solutions to inherently complex problems." For this charge to be upheld, it must be shown explicitly and in detail how this other information is to be used, and evidence must be produced to support the proposed complex approach. As far as this author knows, there is essentially no evidence sorting out the separate effects of various components of monetary aggregates.
} 
monetary base (member bank reserves plus currency held by the public and nonmember banks), and several other figures that can be computed.

While these various aggregates are highly correlated over substantial periods of time, they show significantly different trends for short periods. In selecting an aggregate, the most important considerations are the theoretical relevance of the aggregate and the extent to which the theoretical notions have been given empirical support. Both of these considerations point to the selection of the narrowly defined money stock.

The most important theoretical dispute is between those who emphasize the importance of bank deposit liabilities—the "monetary" viewand those who emphasize the importance of banks' earning assets-the "credit" view. This controversy, which dates back well into the 19th century, is difficult to resolve because historically banks have operated on a fractional reserve basis and so have had both earning assets and deposit liabilities. Since balance sheets must balance, bank credit and bank deposits are perfectly correlated except insofar as there are changes in nonearning assets-such as reserves-or nondeposit liabilities-such as borrowing from the Federal Reserve System. If these factors never changed, the perfect correlation between bank deposits and bank credit would make it impossible ever to obtain evidence to distinguish between the monetary and the credit views. Since the correlation, while not perfect, has historically been very high, it has been very difficult to obtain evidence. Hence, it is still necessary to place major reliance on theoretical reasoning.

There would be little reason to examine the issue closely if we could be confident that the very high correlation between deposits and bank credit would continue into the indefinite future. But there are already substantial differences in the short-run movements of bank credit and bank deposits, and these differences are likely to become greater and of a longer-term character in the future. Banks are raising increasingly large amounts of funds through nondeposit sources such as sales of commercial paper and of capital certificates and through borrowing from the Euro-dollar market and the Federal Reserve System. (Borrowings from the System would probably expand significantly if proposed changes in discount-window administration were implemented.)

The easiest way to examine the theoretical issues is to consider some hypothetical experiments. Consider first the experiment in which the Federal Reserve raises reserve requirements by $\$ 10$ billion at the initial level of deposits but simultaneously buys $\$ 10$ billion in U.S. government securities in the open market. Deposits need not change, but banks must hold more reserves and fewer earning assets. Under the monetary view the effects would be nil (except for very minor effects examined below) because deposits would be unchanged, but under the credit view the effect would be a tendency for income to contract because bank credit would be lower.

The monetary view is easily explained. Suppose first that the banks initially hold U.S. government securities in excess of $\$ 10$ billion. When reserve requirements are raised, the banks simply sell $\$ 10$ billion of these securities, and this is exactly the amount being purchased by the Federal Reserve. Thus, since deposits are unchanged and bank loans to the nonbank private sectorhereinafter called simply the "private sector"are also unchanged, there should be no effects on that sector.

Now suppose that the banks do not have $\$ 10$ billion in government securities. In this case they must sell private securities, say corporate bonds, to the private sector. The private sector obtains the funds to buy these bonds from the sale of $\$ 10$ billion of government securities to the Federal Reserve. The amount of credit in the private sector is again unchanged. The banks own fewer private securities, while the public owns more private securities and fewer government securities.

Thus, the amount of credit extended to the private sector need not change at all even though bank credit falls. However, two minor effects are possible: First, the Federal Reserve purchase of government securities changes the composition of portfolios. Thus, even if banks have over $\$ 10$ billion of government securities, they may be expected to adjust their portfolios by selling some government securities and some private securities. For ease of exposition, run-offs of loans may be 
included in the sale of private securities. The net result, then, is that the banks have more reserves, fewer government securities, and fewer private securities; the private sector has fewer government securities and fewer liabilities to the banks. The private sector may have-but it will not necessarily have-fewer claims within the sector. It is quite possible that private units may substitute claims on other private units for the government securities sold to the Federal Reserve.

Looked at from the liability side, those units initially with liabilities outstanding to banks may have those liabilities shifted to other private sector units. This occurs, of course, when banks sell securities to the private sector or allow loans to run off that are then replaced by firms selling commercial paper to other firms, drawing on sources of trade credit, and/or borrowing from nonbank financial institutions. A net effect can occur only when the combined portfolios of banks and the private sector contain fewer government securities, though more reserves, than before; such a change may be looked upon as a reduction in liquidity and thereby lead to a greater demand for money and a reduced willingness to undertake additional expenditures on goods and services.

The second effect of the hypothetical experiment being discussed is that bank earnings will be reduced by the increase in reserve requirements. Banks will eventually adjust by raising service charges on demand deposits and/or reducing interest paid on time deposits. For simplicity, assume that the change in reserve requirements applies only to demand deposits so that there is no reason for banks to change the interest paid on time deposits. With higher service charges on demand deposits, lower interest rates on securities are required if people are to hold the same stock of money as before. Since the hypothetical experiment assumed that deposits did not change, interest rates must fall by the same amount as the increase in service charges, an effect that will tend to expand investment and national income.

The portfolio effect tends to contract income while the service charge effect tends to expand income. These effects individually seem likely to be small, and the net effect may well be nil. In this regard, it is interesting to note that the rela- tionship of velocity to the Aaa corporate bond rate is about the same for observations in the 1950's as in the 1920's (Latané, 1954, 1960) in spite of the enormous changes in financial structure and in government bonds outstanding.

Consider another hypothetical experimentone that is in fact not so hypothetical at the current time. Suppose that banks suddenly start issuing large amounts of commercial paper and investing the proceeds in business loans. It is possible that the loans simply go to corporations that have stopped issuing their own commercial paper. In this case the bank would be purely a middleman with no effect on the aggregate amount of commercial paper outstanding. The increase in bank credit would not represent an increase in total credit.

But, of course, banks issuing commercial paper must perform some function. This function is clearly that of increasing the efficiency of the financial sector in transferring funds from the ultimate savers to the ultimate borrowers. The efficiencies arise in several ways. First, under fractional reserve banking, banks have naturally developed expertise in lending. It is efficient to make use of this expertise by permitting banks to have more lendable funds than they would have if restricted to demand deposits alone. The efficiency takes the form of fewer administrative resources being required to transfer funds from savers to borrowers.

The second form of efficiency results from the fact that financial markets function best when there is a large amount of trading in a standardized instrument. For example, the shares of large corporations are much more easily marketed than those of small corporations. Many investors want, and require, readily marketable securities, and they can be persuaded to buy securities in small firms only if the yields are high. As a result funds may go to large corporations to finance relatively low-yielding investment projects while highyielding projects available to small firms cannot be financed. Commercial banks, and other financial intermediaries, improve the allocation of capital by issuing relatively standardized securities with good markets and lending the proceeds to small firms. 
The question is whether there is any effect on economic activity from an increase in bank credit financed by commercial paper-assuming that the money stock is not affected. To begin with, it must be emphasized that an increase in the efficiency of investment does not necessarily affect the total of investment. The same resources may be absorbed either in building a factory that will produce a product that cannot be sold or in building a factory to produce a highly profitable product in great demand.

Banks, and financial intermediaries in general, have the effect of reducing somewhat the cost of capital for small firms. Because intermediaries bid funds away from large corporations, the cost of capital for large corporations tends to be somewhat higher than it would be if there were no intermediaries. At this stage in the analysis the net effect on investment is impossible to predict since it depends on whether the reduction in investment by large corporations is larger or smaller than the increase in investment by small corporations.

In examining the effects of intermediation, however, another factor must be considered. Suppose it is assumed that the interest rates relevant for the demand for money are rates on high-quality securities. It was argued above that intermediation tends unambiguously to raise the yields on highquality securities above what they otherwise would be. Since the assumption throughout has been that the stock of money is unchanged, the level of income must increase if the quantity of money demanded is to be unchanged with the higher interest rate of high-quality securities. The conclusion, therefore, is that the increase in bank credit is expansionary in the hypothetical experiment being discussed.

This conclusion, however, does not warrant the further conclusion that bank credit is the appropriate monetary aggregate for policy purposes. The effect examined above occurs when any financial intermediary expands. Not only is there the problem that data for all intermediaries are simply not available on a current basis but also there are serious problems in even defining an intermediary. A particularly good example of this difficulty is afforded by trade credit. A large nonfinancial corporation may advance trade credit to customers, many of whom may be small, and may also advance funds to suppliers through prepayments. The large corporation finances these forms of credit through the sale of securities, or through retained earnings diverted from its own investment opportunities and/or from dividends. In this case the large corporation is serving exactly the same function as the financial intermediaries are. But tracing these credit flows is obviously impossible at the present time.

Another problem with bank credit as a guide to policy is that changes in bank credit depend both on changes in bank deposits and on changes in nondeposit sources of funds. As demonstrated by the hypothetical experiments examined above, the effect of a change in bank credit depends heavily on whether or not deposits change.

One final hypothetical experiment will be considered. Suppose the U.S. Treasury sells additional government securities to the public to finance an increase in cash balances at commercial banks. Since banks have received no additional reserves, total deposits cannot change. Deposits owned by the public are transferred to the Treasury. Bank credit is unchanged, but the impact on the private sector is clearly contractionary. The private sector holds more government bonds and fewer deposits. Equilibrium can be restored only through some combination of a rise in interest rates and a decline in income.

The conclusion is that it appears to be fundamentally wrong for policymakers to place primary reliance on bank credit. This is not to say that there is no information to be gained from analysis of bank and other credit flows. However, selection of bank credit as the monetary aggregate would be a mistake. Instead, information on credit flows may be used to adjust the desired rate of growth of the money stock, however it is defined, although it is not clear that the knowledge presently exists as to how to interpret credit flows.

From this analysis it appears that neither bank credit nor any deposit total that includes Treasury deposits is an appropriate monetary aggregate for monetary policy purposes. Before considering the narrow and broad definitions of 
the money stock, let us examine the monetary base, total reserves, and unborrowed reserves.

It is clear that different levels of the money stock may be supported by the same level of the monetary base. Given the monetary base, different levels of the money stock result from changes in reserve requirement ratios; from shifts of deposits between demand and time, which of course are subject to different reserve requirement ratios; from shifts of deposits among classes of banks with different reserve ratios; and from shifts between currency and deposits. These effects are widely understood, and they have led to the construction of monetary base figures adjusted for changes in reserve requirements. Similar adjustments are applied to total and nonborrowed reserves. If enough adjustments are made, the adjusted monetary base is simply some constant fraction of the money stock, while adjusted reserves are some constant fraction of deposits. It is obviously much less confusing to adopt some definition of the money stock as the appropriate aggregate rather than to use the adjusted monetary base or an adjusted reserve figure.

There can be no doubt that FOMC instructions to the Manager in terms of nonborrowed reserves would be more precise and more easily followed than instructions in terms of the money stock. But the simplicity of reserve instructions would disappear if adjusted reserves were used, for then the Manager would have to predict such factors as shifts between demand and time deposits, the same factors that must be predicted in controlling the money stock. No one would argue that such factors-and others such as changes in bank borrowings and shifts in Treasury deposits-should be ignored. If the FOMC met daily, instructions could go out in unadjusted form with the FOMC making the adjustments. But surely this technical matter should be handled not by the FOMC but by the Manager and his staff in order to permit the FOMC to concentrate on basic policy issues.

The only aggregates left to consider are the narrowly and broadly defined money stocks. There is a weak theoretical case favoring the narrow definition because time deposits must be transferred into demand deposits or currency before they can be spent. The case is weak because the cost of this transfer is relatively low. If the cost were zero, then there would be no effective distinction between demand and time deposits. Indeed, since time deposits earn interest, all funds would presumably be transferred to time deposits.

No strong empirical case exists favoring one definition over the other. The broad and narrow money stocks are so highly correlated over time that it is impossible to distinguish separate effects. It appears, however, that there is a practical case favoring the adoption of the narrow money stock. Time deposits include both passbook accounts, which can be readily transferred into demand deposits, and certificates of deposit, which cannot. Since CD's appear to be economically much more like commercial paper than like passbook time accounts, they ought to be excluded from the broadly defined money stock.

There is, of course, no reason why CD's cannot be excluded from the definition of money. The problem is that banks may in the future invent new instruments that will be classified as time deposits for regulatory purposes but that are not really like passbook accounts. In retrospect it may be clear how the new instrument should be treated, but the situation may be confused for a time. The same sort of problem exists with demand deposits—consider the compensating balance requirements imposed by many banksbut it seems likely that the problem will remain more serious for time deposits.

In summary, there is a strong case favoring the selection of some definition of the money stock as the monetary aggregate, and there appears to be a marginal case for preferring the narrowly defined money stock.

\section{Technical Problems of Controlling Money Stock}

In the preceding sections it has been argued that the monetary policy control instrument should be the money stock. The purpose of this section is to investigate some of the technical problems in controlling the money stock. The first topic examined is that of the form of instructions to the Manager of the System Open Market Account. Following this discussion is an exami- 
nation of the feedback method of control. Finally, there is an examination of the significance of data revisions. All of this discussion is in terms of the narrowly defined money stock, but much of it also applies to other aggregates.

Specification of the Desired Money Stock. There are two major issues connected with the form of FOMC instructions to the Manager. The first is whether the desired money stock should be expressed in seasonally adjusted or unadjusted form, while the second is whether the desired money stock should be expressed in terms of a complete path week by week over time or of an average over some period of time. The first issue turns out to be closely related to the question of data revisions, and so its discussion will be deferred for the moment. It is to the second issue that we now turn.

Since required reserves are specified in terms of a statement-week average, the statement week is the natural basic time unit for which to measure the money stock, and the measure takes the form of the average of daily money stock figures over the statement week. The fact that daily data may not be available on all components of the money stock does not affect the argument; however estimated, the weekly-average figure is the most appropriate starting point in the analysis.

The weekly money stock is clearly not subject to precise control because of data lags and uncontrollable random fluctuations. Furthermore, no one believes that these weekly fluctuations have any significant impact. The natural conclusion to be drawn is that there is no point in specifying instructions in terms of weekly data but rather that some average level over a period of weeks should be used. Upon closer examination, however, this conclusion can be shown to be unjustified.

The difficulty in expressing the instructions in terms of averages can be explained very simply by two examples. To keep the examples from becoming too complicated, it will be assumed that instructions take the form of simple rates of growth on a base money stock of $\$ 200$ billion. The neglect of compounding makes no essential difference to the argument.

For the first example, assume that the policy instruction is for a growth rate of 4 percent per annum, which is $\$ 8$ billion per year or about $\$ 154$ million per week. If the money stock grew by $\$ 154$ million per week for 8 weeks, then the figure for the eighth week would be above the base week figure by an amount representing a 4 percent annual growth rate. The average of weeks 5 through 8 would be above the average of weeks 1 through 4 by $\$ 616$ million, an amount also representing a 4 percent annual growth rate. So far, there is no reason to favor the path specification over a specification in terms of 4-week averages.

Now suppose that the increase in weeks 1 through 4 was on schedule, but that a large uncontrollable increase of $\$ 500$ million occurred in the fifth week. Starting from a base-week figure of $\$ 200$ billion, the average money stock for weeks 1 through 4 would be $\$ 200.385$ billion, and if the instruction were in terms of 4-week averages it would specify an average money stock of $\$ 201.001$ billion for weeks 5 through 8 .

Since by hypothesis the money stock grew by $\$ 154$ million in each of the first 4 weeks, in the fourth week the level was $\$ 200.616$ billion. The jump of $\$ 500$ million in the fifth week would take the level to $\$ 201.116$ billion, a figure already above the desired average of $\$ 201.001$ billion for weeks 5 through 8 . To reach this desired average given the jump in week 5 , the money stock in weeks 6 through 8 would have to average less than $\$ 201.001$ billion, and so the money stock would have to be forced below the level of the fifth week for weeks 6 through 8. Furthermore, as the reader may calculate, it would be necessary to have higher than normal weekly growth in weeks 9 through 12 if the average of these weeks were to be above the average of weeks 5 through 8 by $\$ 616$ million. On the other hand, if the instruction were in terms of the desired weekly path, the instruction would read that the desired money stock in the eighth week was $\$ 201.232$ billion, and therefore the Manager would not have to force the money stock down in weeks 6 through 8. Instead, he could aim for a growth of about $\$ 39$ million in each of the weeks 6 through 8 to bring the level in week 8 to the desired figure of $\$ 201.232$ billion.

From this example it can be seen that specification in terms of averages of levels of the money 
stock forces the Manager to respond to random fluctuations in a whipsawing fashion. Since week-by-week fluctuations have essentially no significance, there is no point in wrenching the financial markets in order to undo a random fluctuation. If averaging is to be used, the average should be specified in terms of the desired average weekly change over, say, the next 4 weeks rather than in terms of the average level of the next 4 weeks. Specification in terms of the average weekly change is equivalent to a specification stating that the Manager should aim for a particular target level in the fourth week.

The second example illustrating the hazards of specification in terms of the average level will show what happens when policy changes. As before, assume that the money stock in the base week is $\$ 200$ billion and that the desired growth is at a 4 percent rate in weeks 1 through 4 . In this example it is assumed that there are no errors in hitting the desired money stock. Thus, the money stock is assumed to grow by $\$ 154$ million per week, reaching a level of $\$ 200.616$ billion in the fourth week and an average level of \$200.385 billion for weeks 1 through 4 .

Now suppose that in week 4 the FOMC decides on a policy change and specifies a 1 percent growth rate for the money stock for weeks 5 through 8. If the specification were in terms of the average level, then it would require an increase in the average level of $\$ 154$ million, which would bring the average level to $\$ 200.539$ billion for weeks 5 through 8 . But the figure for week 4 is already $\$ 200.616$ billion, and so the money stock in weeks 5 through 8 would have to average less than the figure already achieved in week 4 .

Thus, after a steady 4 percent growth week by week, an average-level policy specification would actually require a negative week-by-week growth before the new 1 percent growth rate could be achieved. On the other hand, a policy specification in terms of the weekly path would require a weekly growth of $\$ 38.5$ million each week for weeks 5 through 8.

To make the point clear, this example was constructed so that the policy shift from a 4 to a 1 percent growth rate would actually require a negative growth rate for a time on a week-by-week basis when the instructions are in terms of average levels. In general, when average levels are used, a policy shift to a lower growth rate will require in the short term a growth rate lower than the new policy rate set, and a policy shift to a higher growth rate will require a short-term growth rate above the new policy rate. Since policymakers will typically want to shift policy gradually, the levels specification is especially damaging because it in fact instructs the Manager to shift policy more rapidly than the policymakers had desired. It should be noted that the larger the number of weeks included in the average-level specification, the more severe this problem becomes.

Because the money stock cannot be controlled exactly, there is a natural tendency to feel that instructions stated in terms of averages are more attainable. In actuality, of course, this effect is illusory; averaging produces a smaller number to measure the errors, but does not improve control. Nevertheless, if averages are to be used in the instructions, the above examples demonstrate that the averages should be calculated in terms of weekly (or perhaps monthly) changes but not in terms of averages of levels.

Use of average changes does have one advantage, however. An instruction in this form permits the Manager to correct an error in week 1 over the next few weeks rather than instructing him to correct the error entirely in week 2 . As explained above, an instruction in terms of the average weekly change over the next 4 weeks is equivalent to an instruction in terms of the desired level in week 4 , leaving unspecified the desired levels in weeks 1 through 3.

Control Through the Feedback Principle. It is useful to begin by comparing the problems of controlling the money stock with the problems of controlling interest rates. In controlling interest rates, the availability of continuous readings on rates makes it possible for the Manager to exercise very accurate control without understanding the causes of rate changes. Being in continuous contact with the market, the Manager can intervene with open market purchases or sales as soon as the federal funds rate, the Treasury bill rate, or any other rate starts to change in an undesirable fashion. This feedback control is not exact 
since interest rate information arrives with some lag, and there are other lags such as the time required to decide upon and execute an open market transaction and the time it takes for the market to react to the transaction.

More precise control over interest rates could be achieved if the Manager were willing to announce Federal Reserve buying and selling prices for, say, 3-month Treasury bills available to all comers. This is essentially the way in which government securities were pegged during World War II. In principle, there is no reason why such a peg could not be operated in peacetime, although it would certainly be desirable to change the peg frequently, perhaps as often as every day or even every hour. However, in terms of actual behavior of interest rates there is no significant difference between a frequently adjusted peg and continuous intervention by the Manager as described in the previous paragraph.

The main point of this discussion of interest rate control is to emphasize that with frequent interest rate readings it is not necessary to know exactly what causes interest rate changes. In time the Manager develops a feel for the market that enables him to guess accurately which interest rate changes are temporary and which are likely to be "permanent" and so require offsetting open market operations. Furthermore, his feel for the market will enable him to know how large the operations should be. Finally, when he guesses wrongly on these matters, his continuous contact with the market enables him to correct mistakes rapidly.

The same arguments apply to controlling the money stock. The difference between interest rate control and money stock control is a matter of degree rather than kind. Data on the money stock become available with a greater lag, and the data are more subject to revision. But since it is not necessary to control the money stock down to the last dollar, the question is whether it is technically possible to have control that is accurate enough for policy purposes. The answer to this question would certainly appear to be in the affirmative.

The weekly-average figure for the money stock is released to the public 8 days following the end of the week to which the average refers. Of course, data are available internally with a shorter lag. Since the policy rule in the previous section is based on controlling the monthly-average money stocks it would appear that the data are at the present time available with a short enough lag that feedback methods of control are feasible.

To see how feedback control would work, suppose that the Manager were instructed to come as close as possible to a target money stock of $M_{4}^{*}$ in week 4 of a 4 -week operating horizon. The Manager knows that the weekly change in the money stock depends on open market purchases, $P$, which he controls, and many other factors as well, which for simplicity of exposition will be denoted by one factor, $z$. These factors cannot be predicted exactly, and so the Manager will think of $z$ as consisting of a predictable part, $\hat{z}$, and an unpredictable part, $u$. These relationships may be expressed as

$$
\Delta M=\alpha P+z=\alpha P+\hat{z}+u
$$

where $\alpha$ is the coefficient giving the change in money per dollar of open market purchases.

If there were no errors in measuring the money stock, the analysis could be completed on the basis of equation 5 . But of course there are errors in measuring the money stock. To analyze the significance of measurement errors, let $M_{i}$ be the money stock for week $i$ as measured at the end of week $i .{ }^{18}$ Also, let $M_{i}^{f}$ be the final "true" money stock figure for week $i$, and let $e_{i}=M_{i}^{f}-M_{i}$.

The Manager starts out the 4-week period with an estimated money stock of $M_{0}$ for week zero. Of course, the figure for $M_{0}$ is a preliminary one, but revisions in this figure as more data accumulate will affect the estimates for the money stock in later weeks and so affect the Manager's actions in later weeks. It will be assumed that he wants to increase the money stock by equal amounts in each week to reach the desired figure of

\footnotetext{
${ }^{18}$ If a money stock estimate is not directly available at the end of week $i$, one can be constructed by taking the estimate from actual deposit data for week $i-1$ and adding to it a projection for the effects of open market operations and other factors for week $i$. This projection would, of course, come from equation 5 .
} 
$M_{4}^{*}$ in week 4 . In week 1 , therefore, he wants to produce a change in the money stock $1 / 4\left(M_{4}^{*}-M_{0}\right)$. Substituting this figure into equation 5 we obtain

$$
\frac{1}{4}\left(M_{4}^{*}-M_{0}\right)=\alpha P_{1}+\hat{z}_{1}+u_{1}
$$

Thus, the Manager sets $P_{1}$ according to

$$
P_{1}=\frac{1}{\alpha}\left[\frac{1}{4}\left(M_{4}^{*}-M_{0}\right)-\hat{z}_{1}\right]
$$

At the end of the first week the Manager has the estimate, $M_{1}$, for the money stock for that week, and again it is assumed that he wants to spread the desired change $M^{*}-M_{1}$ equally over the next 3 weeks. Thus, the Manager sets $P_{2}$ according to

$$
P_{2}=\frac{1}{\alpha}\left[\frac{1}{3}\left(M_{4}^{*}-M_{1}\right)-\hat{z}_{2}\right]
$$

Similarly, he sets $P_{3}$ and $P_{4}$ according to equations 8 and 9.

$$
\begin{aligned}
& P_{3}=\frac{1}{\alpha}\left[\frac{1}{2}\left(M_{4}^{*}-M_{2}\right)-\hat{z}_{3}\right] \\
& P_{4}=\frac{1}{\alpha}\left[\left(M_{4}^{*}-M_{3}\right)-\hat{z}_{4}\right]
\end{aligned}
$$

From equations 9 and 5 it can be seen that the actual money stock in week 4 is

$$
M_{4}^{f}=M_{3}^{f}+M^{*}-M_{3}-\hat{z}_{4}+z=M_{4}^{*}+e_{3}+u_{4}
$$

This expression for the fourth week of a planning period generalizes to the $n$th week of a planning period of any length merely by replacing the subscript 4 by the subscript $n$. We can, therefore, express the annual rate of growth, $g$, over an $n$ week period by

$$
\begin{aligned}
g & =\frac{52}{n}\left(\frac{M_{n}^{f}-M_{0}^{f}}{M_{0}^{f}}\right) \\
& =\frac{52}{n}\left(\frac{M_{n}^{*}-M_{0}^{f}}{M_{0}^{f}}\right)+\frac{52}{n}\left(e_{n-1}+u_{n}\right)
\end{aligned}
$$

From equation 11 it can be seen that the actual growth rate, $g$, equals the desired growth rate plus an error term that becomes smaller as $n$ becomes larger.
This analysis shows that a feedback control system that continuously adjusts open market operations as data on the money stock in the recent past become available can achieve a target rate of growth with a margin of error that is smaller the longer the period over which the rate of growth is calculated. It also provides a framework in which to examine the relative importance of operating errors, the $u_{i}$, and data errors, the $e_{i}$.

To obtain an accurate estimate of the sizes of these errors is beyond the scope of this study. However, a very crude method may be used to obtain an estimate of the maximum size of the total error. Monthly money stock changes at annual rates were computed for the period January 1951 through September 1969 on the basis of seasonally adjusted data. This time period yields a total of 225 monthly changes. Then each monthly change was expressed in terms of its deviation from the average of the changes for the previous 3 months. For example, the September deviation was calculated by subtracting from the September monthly change the average of the changes for August, July, and June. The use of deviations allows in part for longer-run trends in the money stock, which trends are assumed to be readily controllable. Since the deviations were calculated over a period during which little or no attention was paid to controlling the money stock, they surely represent an upper limit to the degree of volatility in the money stock to be expected under a policy directed at control of the money stock.

These monthly deviations have a standard deviation of 3.12 percent per annum. Applying equation 11, except for replacing 52 by 1 to reflect the fact that the rates of change were expressed at annual rates in the first place, it is found that the standard deviation over a 3-month period would be 1.04 percent per annum. If it is assumed that these deviations are normally distributed, the conclusion is that over 3-month periods the actual growth rate would be within plus or minus 1.04 percent of the desired growth rate about 68 percent of the time, and would be within plus or minus 2.08 percent about 95 percent of the time. Inasmuch as these limits would be cut in half over 6-month periods, the actual growth rate 95 percent of the time would be in the range of plus 
or minus 1.04 percent of the desired growth rate. ${ }^{19}$ When it is recalled that these calculations are based on an estimate of variability over a period in which very little attention was paid to stabilizing money stock growth rates, it is clear that fears as to the ability of the Federal Reserve to control the money stock accurately are completely unfounded. ${ }^{20}$

This conclusion justifies the approach used at the beginning of this section on the selection of a monetary aggregate, at least for the narrowly defined money stock and most probably for other aggregates as well. That approach, it will be recalled, analyzed the selection issue on the assumption that every one of the aggregates considered could be precisely controlled for all practical purposes. There can be no doubt that errors in reaching targets for goal variables such as GNP, at the present state of knowledge, are due almost entirely to incomplete knowledge of the relationships between instrument variables (such as various aggregates and interest rates) and the goal variables, and hardly at all to errors in setting instrument variables at desired levels.

\section{Problems of Data Revisions and Changing} Seasonality. Another topic that needs examination is the effect of data revisions. While weeklyaverage data are released with an 8-day lag, these figures are subject to revision. Not much weight can be given to early availability of data that are later revised substantially. To investigate this problem, two money stock series were compared, one "preliminary" and one "final." Since the analysis below is based on published monthly data, it obviously provides little insight into the

${ }^{19}$ If the calculations are based on the variability of the monthly changes themselves rather than on the deviations of the monthly changes, the results are not greatly changed. The standard deviation of the monthly changes over the same period used before is 3.53 per cent per annum, which yields a 95 percent chance of the growth rate being in a range around the desired rate of plus or minus 2.36 (1.18) per cent per annum for 3-month (6-month) periods.

${ }^{20}$ Compare "First, however, it may be worthwhile to touch on the extensively debated subject whether the Federal Reserve, if it wanted to, could control the rate of money supply growth. In my view, this lies well within the power of the Federal Reserve to accomplish provided one does not require hair-splitting precision and is thinking in terms of a time span long enough to avoid the erratic, and largely meaningless, movements of money supply over short periods" (Holmes, 1969, p. 75). accuracy of weekly data. However, since policy instructions may be based on monthly data, the analysis is of some value in assessing data accuracy. Furthermore, the conclusions on the importance of revisions in seasonal factors can be expected to hold for the weekly data.

A "preliminary" series of monthly growth rates of the money stock was constructed by calculating the growth rate for each month from data reported in the Federal Reserve Bulletin for the following month. For example, the Bulletin dated September reports money stock data for 13 months through August; it is the annual rate of change of August over July that is called the "preliminary" August rate-of-change observation. The "final" series is the annual rate of growth calculated from the monthly money stock series covering 1947 through September 1969, reported in the Federal Reserve Bulletin for October 1969, pp. 790-93. Data were gathered on both a seasonally adjusted basis and an unadjusted basis for January 1961 through August 1969.

The correlation between the preliminary and final seasonally adjusted series is 0.767 , while for the unadjusted series the correlation is 0.997 . Another way to compare the preliminary and final series is to examine the differences in the two series. ${ }^{21}$ For the seasonally adjusted data, the differences have a mean of 0.122 and a standard deviation of 3.704, and the mean absolute difference is 2.891. On the other hand, for the seasonally unadjusted data the differences have a mean of 0.150 and a standard deviation of 1.366, and the mean absolute difference is $0.955 .^{22}$

These results make it abundantly clear that the major reason why the preliminary and final

\footnotetext{
21 The analysis of the differences inadvertently runs from February 1961 through August 1969 while the correlation analysis runs from January 1961 through August 1969.

${ }^{22}$ To take account of the fact that the "final" money stock series may be further revised for months near the October 1969 publication date of this series, the analysis of differences between the preliminary and final series was also run on the period February 1961 through December 1968. The mean difference, the standard deviation of the differences, and the mean absolute difference, are, respectively, for the seasonally adjusted data 0.026, 3.779, and 2.922 , while the figures for the seasonally unadjusted data are $0.038,1.280$, and 0.890 . In spite of the fact that the "final" series is not really final for 1969 data, the average differences are generally larger for the longer period due to the relatively large data revisions in the middle of 1969.
} 
figures on the money stock differ is revision of seasonal adjustment factors. While such revisions may produce substantial differences between preliminary and final monthly growth rates, the differences must be lower for the average of several months' growth rates. The reason, of course, is that revision of seasonal factors must make the figures for some months higher and those for other months lower, leaving the annual average about unchanged.

The significance of revisions in seasonal factors can be understood only after a discussion of the significance of seasonality for a money stock rule. If the monetary rule were framed in terms of the seasonally unadjusted money stock, the result would be to introduce substantially more seasonality into short-term interest rates than now exists. It can be argued not only that greater seasonality in interest rates would not be harmful but also that it would be positively beneficial. Greater seasonality in interest rates would presumably tend to push production from busy, highinterest seasons into slack, low-interest seasons.

Although the argument for seasonality in interest rates could be pushed further, there is an important practical reason for not initially adopting a money rule stated in terms of the seasonally unadjusted money stock. The reason is that the rule ties the growth rate of the money stock to the seasonally adjusted unemployment rate and to the interest rate. The rule has been developed through an examination of past experience. If the seasonal were taken out of the money stock, a different seasonal would be put into interest rates, and possibly into the unemployment rate as well. Seasonal factors for these variables, especially for the unemployment rate, determined from past data would no longer be correct if the money stock seasonal were removed. Seasonally adjusting the unemployment index by the old factors could produce considerable uncertainty over the application of the monetary rule. Thus, application of the rule through the seasonally unadjusted money stock, if desirable at all, should only come about through gradual reduction rather than immediate elimination of seasonality. A further reason for a gradual approach would be to permit the financial markets to adjust more easily to changed seasonality.
The point of this discussion is not to urge acceptance of a rule framed in terms of the unadjusted money stock, since this step would not be initially desirable in any case. Rather, the point is to emphasize that seasonality is in the money stock only in order to reduce the seasonality of other variables, primarily interest rates. The seasonality of the money stock, unlike variables such as agricultural production, is not inherent in the workings of the economy but rather exists because the Federal Reserve wants it to exist. The money stock can be made to assume any seasonal pattern the Federal Reserve wants it to assume.

The monetary rule should be framed, at least initially, in terms of the seasonally adjusted money stock-using the latest estimated seasonal factors. In subsequent years changes in these seasonal factors should not result from mechanical application of seasonal adjustment techniques to the money stock data but rather should be the result of a deliberate policy choice. The policy choice would be based on the desire to change seasonality of other variables. For example, if it were thought desirable to take the seasonality out of short-term interest rates, the seasonal factors for the money stock would then be changed to take account of changes in tax dates and other factors.

Under a money stock policy, whether or not guided by a monetary rule, revised seasonal factors cannot properly be applied to past data. If the changes are applied to past data with the result that some monthly growth rates of adjusted data become relatively high while others become relatively low, the conclusion to be drawn is not that policy was mistaken as a result of using faulty seasonal factors. Instead, the conclusion is merely that seasonal policy differed in the past from current policy or from the seasonal pattern assumed by the investigator who computed the seasonal factors. Seasonal policy can be shown to be "wrong" only by showing that undesirable seasonals exist in other variables.

One final problem deserves discussion. While it appears from the analysis of seasonally unadjusted money stock data that revisions of the data 
are relatively unimportant, at least from the evidence for 1961-69, how should the policy rule be adjusted when there are major data revisionsas in the middle of 1969? For example, suppose that revisions indicate that monetary growth has been much higher than had been expected, and higher than was desirable. On the one hand, policy could ignore the past high rate of growth and simply maintain the current rate of growth of the revised series in the desired range. On the other hand, the policy could be to return the money stock to the level implied by applying the desired growth rate to the money stock in some past base period. The first alternative involves ratifying an undesirable high past rate of growth, while the second may involve a wrenching change in the money stock to return it to the desired growth path. The proper policy would no doubt have to be decided on a case-by-case basis. However, a useful presumption might be to adopt the second alternative, but to set as the base the money stock 6 months in the past and to return to the desired growth path over a period of several months.

Improving Control Over the Money Stock.

The analysis above has shown that under present conditions the money stock can be controlled quite accurately. However, it should be emphasized that there are numerous possibilities for improving control. Although detailed treatment of this subject is beyond the scope of this study, a few very brief comments appear appropriate.

There are three basic methods for improving control. The first method is that of improving the data. The more quickly the deposit data are available, the more quickly undesirable movements in the money stock can be recognized and corrected. And the more accurate the deposit data, the fewer the mistakes caused by acting on erroneous information. It is clear that expenditures of money on expanding the number and coverage of deposit surveys and on more rapid processing of the raw survey data can improve deposit data.

The second method of improving control is through research, which increases our understanding of the forces making for changes in the money stock. For example, transfers between demand and time deposits might be more accurately predicted through research into the causes of such transfers.

The third method of improving control is through institutional changes. To reduce fluctuations in excess reserves and thereby achieve a more dependable relationship between total reserves and deposits, the federal funds market might be improved by making possible transfers between the East and West Coasts after east coast banks are closed. Also helpful would be a change from lagged to contemporaneous reserve requirements. More radical reforms such as equalization of reserve requirements for city, country, and nonmember banks and elimination of reserve requirements on time deposits should also be considered.

\section{SUMMARY}

\section{Purposes of the Study}

The primary purpose of this study has been to argue that a major improvement in monetary policy would result through a systematic policy approach based on adjustments in the money stock. Equal emphasis has been placed on the "systematic" part and the "money stock" part of this approach. The analysis has proceeded first by showing why policy adjustments should be made through money stock adjustments, and second by showing how these policy adjustments might be systematically linked to the current business situation through a policy guideline or rule-of-thumb. A third, and subsidiary, part of this study is an analysis of the reasons for preferring the money stock over other monetary aggregates, and of some of the problems in reaching desired levels of the money stock.

It has been emphasized throughout that this policy approach is one that is justified for the intermediate-term future on the basis of knowledge now available. The specific recommendations are not intended to be good for all time. Indeed, the approach has been designed to encourage evaluation of the results so that the information obtained thereby can be incorporated into policy decisions in the future. 


\section{The Theory of Monetary Policy Under Uncertainty}

Since policymakers have repeatedly emphasized the importance of uncertainty, it is necessary to analyze policy problems within a model that explicitly takes uncertainty into account. In particular, only within such a model is it possible to examine the important current issue of whether policy adjustments should proceed through interest rate or money stock changes.

A monetary policy operating through interest rate changes sets interest rates either through explicit pegging as was used in World War II or through open market operations directed toward the maintenance of rates in some desired range. Under such a policy the money stock is permitted to fluctuate to whatever extent is necessary to keep interest rates at the desired levels. On the other hand, a policy operating through money stock changes uses open market operations to set the money stock at its desired level while permitting interest rates to fluctuate freely.

If there were perfect knowledge of the relationships between the money stock and interest rates, the issue of money stock versus interest rates would be nonexistent. With perfect knowledge, changes in interest rates would be perfectly predictable on the basis of policy-induced changes in the money stock, and vice versa. It would, therefore, be a matter of preference or prejudice, but not of substance, whether policy operated through interest rates or the money stock.

To analyze the interest versus money issue, then, it is necessary to assume that there is a stochastic link between the two variables. And, of course, this is in fact the case. There are two fundamental reasons for the stochastic link. First, the demand for money depends not only on interest rates and the level of income but also on other factors, which are not well understood. As a result, the demand for money fluctuates in a random fashion even if income and interest are unchanged. If the stock of money is fixed by policy, these random demand fluctuations will force changes in interest and/or income in order to equate the amount demanded with the fixed supply.

The second source of disturbances between money and interest stems from disturbances in the relationship between expenditures-especially investment-type expenditures-and interest rates. Given an interest rate fixed by policy, these disturbances produce changes in income through the multiplier process, and these income changes in turn change the quantity of money demanded. With interest fixed by policy, the stock of money must change when the demand for money changes. On the other hand, if the money stock were fixed by policy, since the expenditure disturbance changes the relationship between income and interest, some change in the levels of income and/or interest would be necessary for the quantity of money demanded to equal the fixed stock.

Money stock and interest rate policies are clearly not equivalent in their effects, given that disturbances in money demand and in expenditures do occur. Since the effects of these policies are different, which policy to prefer depends on how the effects differ and on policy goals. At this level of abstraction, it is clearly appropriate to concentrate on the goals of full employment and price stability. Unfortunately, the formal model that has been worked out, which is examined carefully in Section I above, applies only to the goal of stabilizing income. If "income" is interpreted to mean "money income," then the goals of employment and price level stability are included but are combined in a crude fashion.

The basic differences in the effects of money stock and interest rate policies can be seen quite easily by examining extreme cases. Suppose first that there are no expenditure disturbances, so there is a perfectly predictable relationship between the interest rate and the level of income. In that case, a policy that sets the interest rate sets income, and policymakers can choose the level of the interest rate to obtain the level of income desired. When the interest rate is set by policy, disturbances in the demand for money change the stock of money but not the level of income. On the other hand, if policy sets the money stock, then the money demand disturbances would affect interest and income leading to less satisfactory stabilization of income than would occur under an interest rate policy.

The other extreme case is that in which there are disturbances in expenditures but not in money 
demand. If policy sets the interest rate, expenditure disturbances will produce fluctuations in income. But if the money stock is fixed, these income fluctuations will be smaller. This point can be seen by considering a specific example such as a reduction in investment demand. This disturbance reduces income. But given an unchanged money demand function, with the fall in income, interest rates must fall so that the amount of money demanded will equal the fixed stock of money. The decline in the interest rate will stimulate investment expenditures, thus offsetting in part the impact on income of the initial decline in the investment demand function. With expenditures disturbances, then, to stabilize income, it is clearly better to follow a money stock policy than an interest rate policy.

The conclusion is that the money versus interest issue depends crucially on the relative importance of money demand and expenditures disturbances. It is especially important to note that nothing has been said about the size of the interest elasticity of the demand for money, or of the interest elasticity of investment demand. These coefficients, and others, determine the relative impacts of changes in money demand and in investment and government expenditures when the changes occur. The interest versus money issue does not depend on these matters, however, but only on the relative size and frequency of disturbances in the money demand and expenditures functions. ${ }^{23}$

The analysis above is modified in detail by considering possible interconnections between money demand and expenditures disturbances. It is also true that in general the optimal policy is not a pure interest or pure money stock policy, but a combination of the two. These matters, and a number of others, are discussed in Section I.

\section{Evidence on Relative Magnitudes of Real and Monetary Disturbances}

Resolution of the money versus interest issue depends on the relative size of real and monetary disturbances. Unfortunately, there is no com-

\footnotetext{
${ }^{23}$ For a full understanding of this important point, the reader should refer to the analysis of Section I.
}

pletely satisfactory body of evidence on this matter. Indeed, because of the conceptual difficulties of designing empirical studies to investigate the issue, the evidence is unlikely to be fully satisfactory for some time to come. Nevertheless, by examining a number of different types of evidence, a substantial case can be built favoring the use of the money stock as the policy control variable.

Before discussing the evidence, it is necessary to define in more detail what is meant by "disturbance." Consider first a money demand disturbance. The demand for money depends on the levels of income and of interest rates, and on other variables. The simplest form of such a function uses GNP as the income variable, and one interest rate-say the Aaa corporate bond rate-and all other factors affecting the demand for money are treated as disturbances. To the extent possible, of course, these other factors should be allowed for, but for policy purposes these factors must be either continuously observable or predictable in advance so that policy may be adjusted to offset any undesirable effects on income of these other factors. Factors not predictable in advance must be treated as random disturbances.

Similarly, expenditures disturbances are defined as the deviations from a function linking income to the interest rate and other factors. These other factors would include items such as tax rates, government expenditures, strikes, and population changes. Again, for policy purposes these factors must be forecast, and so errors in the forecasts of these items must be included in the disturbance term. It is important to realize that the disturbances will be defined differently for scientific purposes ex post because the true values of government spending and so forth can be used in the functions once data on these items are available.

In the discussion of the theoretical issues above it was noted that an expenditure disturbance would have a larger impact on income under an interest rate policy than under a money stock policy. Simulation of the FR-MIT model provides the estimate that the impact on income of an expenditures disturbance, say in government spending, is over twice as large under an interest rate policy as under a money stock policy. An 
error in forecasting government spending, then, would lead to twice as large an error in income under an interest rate policy. Since there is no systematic record of forecasting errors for variables such as government spending and strikes, there is no way of producing evidence on the size of such forecasting errors. However, after listing the variables that must be forecast, as is done in Section II, it is difficult to avoid feeling that errors in forecasting are likely to be quite significant.

These real disturbances, including forecast errors in government expenditures, strikes, and so forth, must be compared with the disturbances in money demand. The reduced-form studies conducted by a number of investigators provide some evidence on this issue. These studies compare the relative predictive power of monetarist and Keynesian approaches in explaining fluctuations in income. From these studies the predictive power of both approaches appears about equal. However, the predictive power of the Keynesian approach relies on ex post observation of "autonomous" expenditures, and it is clear that these expenditures are subject to forecasting errors ex ante whereas the money stock can be controlled by policy.

The evidence from the reduced-form studies suggests that when forecast errors of autonomous expenditures are included in the disturbance term, the disturbances are larger on the real side than on the monetary side. There are many difficulties with the reduced-form approach and so these results must be interpreted cautiously. Nevertheless, the results cannot be ignored.

The final piece of evidence offered in Section II is a study by the author of the stability of the demand for money function over time. Using a very simple function relating the income velocity of money to the Aaa corporate bond rate, he found that a function fitted to quarterly data for 1947-60 also fits data for 1961-68 rather well. The reader interested in the precise meaning of "rather well" should turn to the technical discussion in Section II.

Evidence on relative stability is difficult to obtain and subject to varying interpretations. No single piece of evidence is decisive, but all the various scraps point in the same direction. The evidence is not such that a reasonable man can say that he has no doubts whatsoever. But since policy decisions cannot be avoided, the reasonable decision based on the available evidence is to adopt the money stock as the monetary policy control variable.

\section{A Monetary Rule for Guiding Policy}

The conclusion from the theoretical and empirical analysis is that the money stock ought to be the policy control variable. For this conclusion to be very useful, it must be shown in detail how the money stock ought to be used. It is not enough simply to urge policymakers to make the "appropriate" adjustments in the money stock in the light of all "relevant" information.

There is no general agreement on exactly what types of adjustments are appropriate. However, it would probably be possible to obtain agreement among most economists that ordinarily the money stock should not grow faster than its long-run average rate during a period of inflation and should not grow slower than its long-run average rate during recession. But many economists would want to qualify even this weak statement by saying that there may at times be special circumstances requiring departures from the implied guideline. Others would say that there is no hope at present of gauging correctly the impact of special circumstances (or even of "standard" circumstances) so that policy should maintain an absolutely steady rate of growth of the money stock.

The basic issues are, first, whether policymakers can forecast disturbances well enough to adjust policy to offset them, and second, the extent to which money stock adjustments to offset short-run disturbances will cause undesirable longer-run changes in income and other variables. The theoretical possibilities are many, but the empirical knowledge does not exist to determine which theoretical cases are important in practice. It is for this reason that a systematic policy approach is needed so that policy can be easily evaluated and improved with experience.

Policy could be linked in a systematic way to a large-scale model of the economy. Target values of GNP and other goal variables could be selected 
by policymakers, and then the model solved for the values of the money stock and other control variables (for example, discount rate) needed to achieve policy goals. While this approach may be feasible in the future, it is not feasible now because a sufficiently accurate model does not exist. Instead, policy decisions are now made largely on the basis of intuitive reactions to current business developments.

Given this situation, the obvious approach is to specify precisely how policy decisions ought to depend on current developments, and this is the approach taken in Section III. The specification there takes the form of a policy guideline, or rule-of-thumb. The proposed rule is purposely simple so that evaluation of its merits would be relatively easy. Routine evaluation of an operating guideline would over time produce a body of evidence that could be used to modify and complicate the rule. But it is necessary to begin with a simple rule because the knowledge that would be necessary to construct a sophisticated rule does not exist.

The proposed rule assumes that full employment exists when the unemployment rate is in the 4.0 to 4.4 percent range. The rule also assumes that at full employment, a growth rate of the money stock of 3 to 5 percent per annum is consistent with price stability. Therefore, when unemployment is in the full employment range, the rule calls for monetary growth at the 3 to 5 percent rate.

The rule calls for higher monetary growth when unemployment is higher, and lower monetary growth when unemployment is lower. Furthermore, when unemployment is relatively high the rule calls for a policy of pushing the Treasury bill rate down provided monetary growth is maintained in the specified range; similarly, when unemployment is relatively low the rule calls for a policy of pushing the bill rate up provided monetary growth is in the specified range. Finally, the rule provides for adjusting the rate of growth of money according to movements in the Treasury bill rate in the recent past. The exact rule proposed is in Table 3 and the detailed rationale for the various components of the rule is explained in the discussion accompanying that table.
The rule is specified throughout in terms of 2 percent ranges for the rate of growth of the money stock on a month-by-month basis. By expressing the rule in terms of a range, leeway is provided for smoothing undesirable interest rate fluctuations and for minor policy adjustments in response to other information. Furthermore, it is not proposed that this rule-of-thumb or guideline be followed if there is good reason for a departure. But departures should be justified by evidence and not be based on vague intuitive feelings of what is needed since the rule was carefully designed from the theoretical and empirical analysis of Sections I and II, and from a careful review of post-accord policy.

There is no way of really testing the proposed rule short of actually using it. However, it is useful to compare the rule with post-accord policy. A detailed comparison may be found in Section III. A summary comparison suggests, however, that for the period January 1952 through July 1968 the rule would have provided a less appropriate policy than the actual policy in only 63 of the 199 months in the period. The rule was judged to be less appropriate if it called for a higherlower-rate of monetary growth than actually occurred and unemployment 12 months hence was below-above-the desired range of 4.0 to 4.4 percent. The rule was also judged less appropriate than the actual policy if actual policy was not within the rule but unemployment nevertheless was in the desired range 12 months hence. The rule actually has slightly fewer errors if the criterion is unemployment either 6 or 9 months following the months in question.

The rule has the great virtue of turning policy around promptly as imbalances develop and of avoiding cases such as the 2.2 percent rate of decline in the money stock from July 1957 through January 1958, during which time the unemployment rate rose from 4.2 percent to 5.8 percent. Furthermore, it seems most unlikely that the rule would produce greater instability than the policy actually followed. Actual policy has, as measured by the money stock, been most expansionary during the early and middle stages of business cycle expansions and most contractionary during the last stages of business expansions and early 
stages of business contractions. Unless a very improbable lag structure exists, the rule would surely be more stabilizing than the actual historical pattern of monetary growth.

\section{Selection and Control of a Monetary Aggregate}

The analysis in this study is almost entirely in terms of the narrowly defined money stock. The reasons for using the narrowly defined money stock as opposed to other monetary aggregates may be stated fairly simply.

Some economists favor the use of bank credit as the monetary aggregate because they view policy as operating through changes in the cost and availability of credit. The major difficulty with this view is that there is no unambiguous way of defining the amount of credit in the economy. And even if a satisfactory definition could be worked out, there is no current possibility of obtaining timely data on the total amount of credit or of controlling the total amount.

The definitional problem arises largely from the activities of financial intermediaries. Suppose, for example, that an individual sells some corporate debentures and invests the proceeds in a fixed-income type of investment fund, which in turn uses the funds to buy the very same debentures sold by the individual. If both the debentures and the investment fund shares are counted as part of total credit, then in this example total credit has risen without any additional funds being made available to the corporation to finance new facilities and so forth.

As another example, it is difficult to see that it would make any substantial difference to aggregate economic activity whether a corporation financed inventories through sales of commercial paper to the public or through borrowing from banks that raised funds through sales of CD's to the public. Since there are numerous close substitutes for bank credit, the amount of bank credit is most unlikely to be an appropriate figure to emphasize. Furthermore, since bank credit is only a small part of total credit there is essentially no possibility of controlling total credit, however defined, through adjustments in bank credit.
Ultimately the issue again becomes that of the stability of various functions. If the demand and supply functions for all of the various credit instruments, including those of financial intermediaries, were stable and were known, then it would be possible to focus on any aggregate that was convenient. For if all the functions were known, then there would be known relationships among various credit instruments, the money stock, and stocks and flows of goods. But the demand and supply functions for the various credit instruments are not known, and it is unlikely that they ever will be known with any degree of precision. There are two basic reasons for this state of affairs. The first, and less important, is that given the great degree of substitutability among credit instruments, substitutions are constantly taking place as a result of changes in regulations, including tax regulations. But second and more important, individual credit instruments are greatly influenced by changes in tastes and technology, factors that economists do not understand well.

As an example of the effects of regulations, consider the substitution in recent years of debentures for preferred stock as a result of the tax laws permitting deduction of interest. As examples of the effects of changes in tastes and technology, consider the inventions of new instruments such as CD's and the shares in dual-purpose investment funds. Furthermore, the relationships among credit instruments will change as attitudes toward risk change due to numerous factors including perhaps fading memories of the last recession or depression.

Money viewed as the medium of exchange seems to be substantially less subject to changes in tastes and technology than do other financial assets. Of course, money is not immune to these problems, as shown by the uncertainty presently existing over the impact of credit cards. But a great deal of empirical work on money has been completed and the major findings have been substantiated by a number of different investigators. And the interpretation of the empirical findings is usually clear because the empirical work has been conducted within the framework of a welldeveloped theory of money. There is, on the other 
hand, no satisfactory theory of bank credit to guide empirical work and to permit interpretation of the significance of empirical findings.

For these reasons, and others, bank credit does not appear to be an appropriate monetary aggregate for policy to control. However, because bank credit and the money stock were so highly correlated in the past, it must be admitted that it probably would not have made much difference which one was used. From recent experience, however, it appears that changes in banks' nondeposit sources of funds are likely to become more, rather than less, important, and so in the future the correlation between money and bank credit is likely to be lower than in the past. If this prediction is correct, then the issue is a significant one.

As a monetary aggregate, to be used for policy adjustments, the money stock has clear advantages over the monetary base and various reserve measures. These aggregates are almost always examined in adjusted form, where the adjustments allow for such factors as changes in the currency/ deposit ratio, in reserve requirements, and in shifts between time and demand deposits. The adjustments are made because the effects of these various factors are understood and are thought to be worth offsetting. The adjustments have the effect of making the base an almost constant fraction of the money stock, or making total reserves an almost constant fraction of demand deposits. It obviously makes more sense to look directly at the money stock, especially since given the nature of the adjustments it is no easier to control the adjusted base or adjusted total reserves than to control the money stock.

The final aggregate to be considered is the broadly defined money stock-the narrow stock plus time deposits. No strong case can be made against the broad money stock. From existing empirical work both definitions of money appear to work equally well. The theoretical distinction between demand deposits and passbook savings deposits depends on the costs of transferring between the two types of deposits, and these costs appear to be quite low. However, CD's do appear to be theoretically different and probably should be excluded from the definition of money. The major reason for excluding all time deposits from the definition is that in the future banks may invent new instruments that will be classified as time deposits for regulatory purposes but for which the matter of definition as money may not be at all clear.

The issue of controllability is a technical one and need not be discussed carefully in this summary. However, two conclusions may be stated. First, instructions from the FOMC to the Manager of the Open Market Account should take the form of a specified average weekly change in the money stock over the period between FOMC meetings. Such an instruction must be distinguished from one in terms of the average level of the money stock over the period between FOMC meetings. The average-level specification has several technical difficulties and should be avoided.

The second conclusion is that it is possible to control the rate of growth of the money stock over a 3-month period in a range of 1 percent on either side of a desired rate of growth. This conclusion is based on an analysis of monthly changes in the money stock over the 1951-68 period, a period during which little or no attention was paid to stabilizing monetary growth, and it takes the historical record at face value. Assuming that efforts to control the money stock would in fact succeed in part rather than make money growth less stable than in the past, the estimate of plus or minus 1 percent is an upper limit to the errors in controlling the growth rate of money over 6month periods.

\section{Concluding Remarks}

The orientation throughout this study has been the redirection of monetary policy on the basis of currently available theory and evidence. The recommendations are not utopian; in the author's view they are supported by current knowledge and are operationally feasible. The approach has been in terms of what ought to be done in the near future, rather than in terms of what might be done eventually if enough information accumulates.

No effort has been made to slide over gaps in our knowledge; rather, the emphasis has been on how policy should be formed given the huge gaps in our knowledge. Indeed, it is precisely these 
gaps in our knowledge that lead to the conclusion favoring policy adjustments through the money stock.

It is the contention of this study that policy can be improved if there is explicit recognition of the importance of uncertainty. As much attention should be given to the consequences of errors in projections as to the projections themselves. Policy may be improved more by "don't know" answers to questions than by projections believed by no one.

This is the static view. If policy can be improved now through greater attention to uncertainty, in the long run it can be improved further only through a reduction in uncertainty. This longer view underlies the proposal for a policy rule-of-thumb. Policy successes and failures ought to be incorporated into a policy design in a form that will repeat the successes and prevent the recurrence of the failures. Policymaking will always require judgment, but the judgment will be applied to changing problems at a moving frontier of knowledge. A systematic formulation of policy will speed the accumulation of knowledge so that the policy problems of today will become the technical staff problems of tomorrow.

\section{REFERENCES}

Andersen, Leonall C. and Jordan, Jerry L. "Monetary and Fiscal Actions: A Test of Their Relative Importance in Economic Stabilization." Federal Reserve Bank of St. Louis Review, November 1968, pp. 11-24.

Ando, Albert and Modigliani, Franco. "The Relative Stability of Monetary Velocity and the Investment Multiplier." American Economic Review, September 1965a, 55, pp. 693-728.

Ando, Albert and Modigliani, Franco. "Rejoinder." American Economic Review, September 1965b, 55, pp. 786-90.

Brainard, William. "Uncertainty and the Effectiveness of Policy." American Economic Review: Papers and Proceedings of the 79th Annual Meeting of the American Economic Association, May 1967, 57, pp. 411-25.
Brunner, Karl and Meltzer, Allan H. "The Federal Reserve's Attachment to the Free Reserve Concept." Subcommittee on Domestic Finance, Banking, and Currency Committee, House of Representatives, 88th Congress, 2nd Session. Washington, DC: Government Printing Office, 1964.

de Leeuw, Frank and Gramlich, Edward. "The Federal Reserve-MIT Econometric Model.” Federal Reserve Bulletin, January 1968, 54, pp. 11-40.

DePrano, Michael and Mayer, Thomas. "Tests of the Relative Importance of Autonomous Expenditures and Money." American Economic Review, September 1965a, 55, pp. 729-52.

DePrano, Michael and Mayer, Thomas. "Rejoinder." American Economic Review, September 1965b, 55, pp. 791-92.

Fels, Rendigs and Hinshaw, C. Elton. Forecasting and Recognizing Business Cycle Turning Points. New York: National Bureau of Economic Research, 1968.

Friedman, Milton and Meiselman, David. The Relative Stability of Monetary Velocity and the Investment Multiplier in the United States, 18971958. Commission on Money and Credit, Stabilization Policies. Englewood Cliffs, NJ: Prentice-Hall, Inc., 1963.

Friedman, Milton and Meiselman, David. "Reply to Donald Hester." Review of Economics and Statistics, November 1964, 46, pp. 369-76.

Friedman, Milton and Meiselman, David. "Reply to Ando and Modigliani and to DePrano and Mayer." American Economic Review, September 1965, 55, pp. 753-85.

Hester, Donald D. “Keynes and the Quantity Theory: A Comment on the Friedman-Meiselman CMC Paper." Review of Economics and Statistics, November 1964a, 46, pp. 364-68.

Hester, Donald D. "Rejoinder.” Review of Economics and Statistics, November 1964b, 46, pp. 376-77.

Holmes, Alan R. "Operational Constraints on the Stabilization of Money Supply Growth,” Controlling 
Monetary Aggregates. Boston: Federal Reserve Bank of Boston, 1969.

Holt, Charles C. "Linear Decision Rules for Economic Stabilization and Growth.” Quarterly Journal of Economics, February 1962, 76, pp. 20-45.

Laidler, David E.W. The Demand for Money: Theories and Evidence. Scranton, PA: International Textbook Company, 1969.

Latané, Henry A. "Cash Balances and the Interest Rate-A Pragmatic Approach.” Review of Economics and Statistics, November 1954, 36, pp. 456-60.

Latané, Henry A. "Income Velocity and Interest Rates-A Pragmatic Approach.” Review of Economics and Statistics, November 1960, 42, pp. 445-49.

Mincer, Jacob, ed. Economic Forecasting and Expectations. New York: National Bureau of Economic Research, 1969.

Moore, Geoffrey H. and Shiskin, Julius. "Indicators of Business Expansions and Contractions." Occasional Paper 103, National Bureau of Economic Research, 1967.

Poole, William. "Optimal Choice of Monetary Policy Instruments in a Simple Stochastic Macro Model.” Quarterly Journal of Economics, May 1970, 84, pp. 197-216.

Reynolds, Lloyd G. Economics. Third Edition. Homewood, IL: Richard D. Irwin, Inc., 1969.

Samuelson, Paul A. Economics. Seventh Edition. New York: McGraw-Hill, 1967.

Theil, Henri. Optimal Decision Rules for Government and Industry. Amsterdam: North-Holland Publishing Company, 1964.

Zarnowitz, Victor. “An Appraisal of Short-Term Economic Forecasting.” Occasional Paper 104, National Bureau of Economic Research, 1967. 
